\title{
Current Neuropharmacology
}

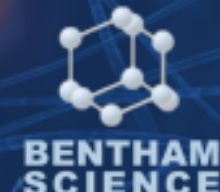

\section{Transgenerational Abnormalities Induced by Paternal Preconceptual Alcohol Drinking. Findings from Humans and Animal Models}

\begin{tabular}{|c|c|}
\hline Journal: & Current Neuropharmacology \\
\hline Manuscript ID & CN-2021-0209.R2 \\
\hline Manuscript Type: & Invited Review \\
\hline $\begin{array}{l}\text { Date Submitted by the } \\
\text { Author: }\end{array}$ & 20-Oct-2021 \\
\hline Complete List of Authors: & $\begin{array}{l}\text { Terracina, Sergio; Università degli Studi di Roma La Sapienza } \\
\text { Ferraguti, Giampiero; Department of Cellular Biotechnologies and } \\
\text { Hematology, Sapienza University of Rome, Italy, } \\
\text { Tarani, Luigi; Università degli Studi di Roma La Sapienza } \\
\text { Messina, Marisa Patrizia; Sapienza University of Rome, Rome Italy, } \\
\text { Department of Sense Organs. Medical Faculty, Sapienza University of } \\
\text { Rome, Italy Viale del Policlinico, } 155 \text { - } 00161 \text { Rome, Italy } \\
\text { Lucarelli, Marco; Università degli Studi di Roma La Sapienza } \\
\text { Vitali, Mario; Università degli Studi di Roma La Sapienza } \\
\text { De Persis, Simone } \\
\text { Greco, Antonio; Sapienza University of Rome, Rome Italy, Department } \\
\text { of Sense Organs. Medical Faculty, Sapienza University of Rome, Italy } \\
\text { Viale del Policlinico, } 155 \text { - O0161 Rome, Italy } \\
\text { Minni, Antonio; Università degli Studi di Roma La Sapienza } \\
\text { Polimeni, Antonella; Sapienza University of Rome, Department of Oral } \\
\text { and Maxillofacial Sciences } \\
\text { Ceccanti, Mauro; Center for Alcohol Abuse (Centro Riferimento Alcologico } \\
\text { Regione Lazio-CRARL), Department of Clinical Medicine, Sapienza } \\
\text { University of Rome, Ital, Clinical Medicine } \\
\text { Petrella, Carla; IBBC - CNR Roma } \\
\text { Fiore, Marco; Institute of Cell Biology and Neurobiology National } \\
\text { Research Council of Italy (C.N.R.), Rome, Fondazione S. Lucia (FSL) } \\
\text { IRCCS, Rome Italy, }\end{array}$ \\
\hline Keywords: & $\begin{array}{l}\text { neurotrophins; , brain, FASD, transgenerational changes, epigenetics, } \\
\text { paternal preconceptual alcohol consumption }\end{array}$ \\
\hline
\end{tabular}

\section{SCHOLARONE ${ }^{\text {m }}$ Manuscripts}




\title{
Transgenerational Abnormalities Induced by Paternal Preconceptual Alcohol Drinking. Findings from Humans and Animal Models
}

\author{
Sergio Terracina ${ }^{1}$, Giampiero Ferraguti ${ }^{1}$, Luigi Tarani ${ }^{2}$, Marisa Patrizia Messina ${ }^{3}$, Marco Lucarelli ${ }^{1}$, \\ Mario Vitali ${ }^{4}$, Simone De Persis ${ }^{5}$, Antonio Greco ${ }^{6}$, Antonio Minni ${ }^{6}$, Antonella Polimeni ${ }^{7}$, Mauro \\ Ceccanti $^{8}$, Carla Petrella ${ }^{9}$ and Marco Fiore*9
}

1 - Department of Experimental Medicine, Medical Faculty, Sapienza University of Rome, Italy

2 - Department of Pediatrics, Medical Faculty, "Sapienza" University of Rome, Italy

3 - Department of Gynecology, Obstetrics and Urology, Sapienza University of Rome, Italy

4 - ASUR Marche, AV4, Ancona, Italy

5 - ASL Rieti, Italy

6 - Department of Sense Organs, Sapienza University Hospital of Rome, Italy

7 - Department of Odontostomatological and Maxillofacial Sciences, Sapienza University of Rome, Italy

8 - SITAC, Società Italiana per il Trattamento dell'Alcolismo e le sue Complicanze, Rome, Italy

9 - Institute of Biochemistry and Cell Biology (IBBC-CNR), Rome, Italy

*Corresponding author:

Marco Fiore, Ph.D.

Institute of Biochemistry and Cell Biology (IBBC-CNR), Rome, Italy

Department of Sense Organs, Sapienza University of Rome, Rome, Italy

Viale del Policlinico, 155 - 00161 Rome, Italy

e-mail: marco.fiore@cnr.it 


\begin{abstract}
Alcohol consumption during pregnancy and lactation is a widespread preventable cause of neurodevelopmental impairment in newborns. While the harmful effects of gestational alcohol use have been well documented, only recently the role of paternal preconceptual alcohol consumption (PPAC) prior to copulating has drawn specific epigenetic considerations. Solid human and animal model data demonstrated that PPAC may affect sperm function eliciting oxidative stress. In newborns, PPAC may induce changes in the behavior, cognitive functions and emotional responses. Furthermore, PPAC may elicit neurobiological disruptions, visuospatial impairments, hyperactivity disorders, motor skill disruptions, hearing loss, endocrine and immune alterations, reduced physical growth, placental disruptions and metabolic alterations. Neurobiological studies on PPAC disclosed also changes in brain function and structure by the disruption of the growth factors pathways. In particular, as shown in animal model studies PPAC alters brain nerve growth factor (NGF) and brainderived neurotrophic factor (BDNF) synthesis and release. This review shows that the crucial topic of lifelong disabilities induced by PPAC and/or gestational alcohol drinking is quite challenging at the individual, societal, and familial levels. Since a nontoxic drinking behavior before pregnancy (for both men and women) during pregnancy and lactation cannot be established the only suggestion for couples planning pregnancies is to completely avoid the consumption of alcoholic beverages.
\end{abstract}

Keywords: neurotrophins; brain; fetal alcohol spectrum disorders; fetal alcohol syndrome; epigenetics; paternal preconceptual alcohol consumption; transgenerational changes.

Running head: fathers and alcohol drinking 


\section{INTRODUCTION}

Alcohol-use disorders (AUD) and alcoholism, are complex multifactorial conditions [1-10] being related also to epigenetic mechanisms [11-18]. Alcohol can modify gene expression through DNA methylation (it enhances the catabolism and loss of methyl groups, which in turn disrupts subsequent SAM-dependent transmethylation reactions of the folate pathway, which are lastly required for DNA methylation), nucleosomal remodeling via histone modifications and microRNA expression. Meanwhile, it has also been observed, similarly to some psychiatric diseases, how persists in adulthood an oxidative stress response mainly at the cellular level (including reactive oxygen species generated as byproducts of cytochrome P450 2E1 (CYP2E1), decreased endogenous antioxidant levels and mitochondrial damage) and a global upregulation of neuroendocrine stress response, regulated by the hypothalamic-pituitary-adrenal axis [5] (Figure 1, point I).

Despite the acknowledgment of the disastrous impact of gestational alcohol abuse on the offspring's health, it is still very common for women and men to drink before and during pregnancy. Indeed, alcohol consumption before conception and during pregnancy and lactation is widely known among the leading preventable causes of neurodevelopmental impairment in the world [19-22]. The umbrella term fetal alcohol spectrum disorders (FASD) is widely used to define such impairments including distinctive craniofacial malformations, central nervous system defects, mental retardation and both prenatal and postnatal growth restriction [23-28]. The terminology FASD is officially adopted to identify a broader spectrum of presentations and disabilities resulting from prenatal alcohol exposure, including a range of categories referred to by the Institute of Medicine (IOM) as alcoholrelated neurodevelopmental disorders (ARND), alcohol-related birth defects (ARBD), the partial fetal alcohol syndrome (pFAS) and finally, the FAS, which is the most serious form [29]. The diagnosis of this clinical condition remains difficult [30-34], it requires a multidisciplinary team and is based on: screening in pregnant and postpartum women; referral of individuals for a possible FASD diagnosis whenever there is the suspect; support to promote abstinence from alcohol; medical assessment including compiling a social and medical history and complete physical examination and 
documentation that the biological mother consumed alcohol during the pregnancy; sentinel facial features; neurodevelopmental assessment in search of evidence of pervasive brain dysfunction [35]. The life expectancy of patients with FAS is estimated to be 34 years (95\% confidence interval: 31 to 37 years) even though the leading causes of death are "external causes" (44\%), which include suicide (15\%), accidents (14\%) and poisoning by illegal drugs or alcohol (7\%) as well as other causes [36]. The observation, in twin and adoption studies, of heritability of about $50 \%$ of alcohol use disorder associated with the demonstration that chronic exposure to ethanol causes chromatin remodeling in the brain that promotes the transition from use to abuse and addiction, render even more challenging the efficacy of prevention campaigns in many situations [37-40]. In the overall population, it has been estimated that about $8.9 \%$ of women drink alcohol during pregnancy, while the global prevalence of FASD is about 1 in 100 people and the prevalence of FAS in the same population is about 14.6 per 10,000 people [27]. It has been calculated that one in every 67 women who consume alcohol during pregnancy would carry a child with FAS, which translates to about 119,000 children born with FAS every year in the world. Provided that FASD is a lifelong disease, it has been estimated that more than 11 million individuals between 0 and 18 years of age, and 25 million individuals between 0-40 years of age, have FASD worldwide [41].

It is now widely established that the harmful effects of prenatal alcohol exposure on the embryo and fetus development cause noticeable cognitive and neurobiological deficits in the newborns, the most common clinical features are listed in Table 1 [42]. The deleterious role of oxidative stress induced by alcohol drinking during pregnancy has been established suggesting how supplementing a mother's diet with protective and antioxidant substances in addition to folic acid, choline, neuroactive peptides, and supportive psychological therapies could protect newborns from being affected $[16,18,43]$.

It has been demonstrated how phenotypic heterogeneity in human FASD is strongly related to a genetic vulnerability in affected brain regions [44]. Interestingly, it has been hypothesized that the principles of non-Mendelian inheritance, or "exceptions" to Mendelian genetics, in particular when 
one parent has an exaggerated influence over the offspring's vulnerability to prenatal alcohol (e.g. maternal alleles leading to an altered intrauterine hormonal environment or when epigenetic regulation of allele-specific gene expression causes an imbalance between the maternal and paternal genetic contributions) could be the main factor determining the severity of the FASD symptomology $[21]$.

While the negative effects of gestational alcohol use have been well documented and known for some time, the capacity of parental life history to influence the offspring phenotype has been highly underestimated and not fully explored [16,26,43,45-47]. Knowing that about $75 \%$ of children with FAS have heavy drinkers or alcoholic biological fathers it seems logical that in recent times it has been gaining a subtle role, in FASD manifestation, of alcohol consumption by fathers before mating [48]. Differently from maternal alcohol exposure, paternal alcohol consumption does not directly come into contact with developing embryos and the direct relationship between paternal alcohol consumption and genetic or epigenetic mutations that result in developmental abnormalities has been studied only recently, challenging the common misconception that sperm does not transmit heritable information beyond the genetic code. In 2004, it was partially investigated the paternal influence on offspring's low birth weight, congenital malformations, deficits of the immune system and, of course, cognitive and behavioral abnormalities including learning and memory deficits, hyperactivity, and poor stress tolerance, resulting in a renewed interest on this topic [48]. Recently many studies have also suggested the existence of 'transgenerational' consequences of alcohol for the offspring, more often related to male chronic alcohol abuse, demonstrating the tendency to epigenetic variations that might be transmitted through multiple generations $[37,49,50]$.

This report aims to provide a summary and subsequent review of past researches, which highlights the evidence on the role of paternal preconceptual alcohol consumption (PPAC) in FASD etiopathogenesis. 


\section{METHODS}

Search strategy: All the studies indexed in PubMed and relevant to identify the paternal alcohol consumption role in FASD were sought using a combination of keywords selected, with authors' agreement, using the PICOS approach: participants, interventions, comparisons, outcomes, and study design [51,52]. The following keywords were used: alcohol-related birth defects, fetal alcohol syndrome, fetal alcohol spectrum disorders, paternal alcohol consumption, preconceptual ethanol consumption, prenatal ethanol exposure. When judged relevant, other items listed in the references of the included articles were considered for eligibility.

Study selection and inclusion criteria: Only full-text articles published in English, analyzing the role of paternal alcohol consumption in FASD in humans or animal models were considered eligible.

Data extraction and data analysis: Investigators independently screened and assessed titles and abstracts before retrieval of the full manuscripts. The selected full papers were reviewed for eligibility according to the inclusion criteria. References in the selected papers were scrutinized for additional articles in a further effort to ensure that relevant publications were not missed. All controversies concerning study selection or data extraction were resolved by consensus with a third group of reviewers. Evidence from available literature is presented in this review in a narrative way to offer a clear overview of the many findings regarding the effects of PPAC and its role in FASD etiopathogenesis. Results are presented distinguishing many organized subchapters and prioritizing findings from human clinical studies when compared to an animal model.

\section{TRANSGENERATIONAL EFFECTS OF PATERNAL PRECONCEPTUAL ALCOHOL CONSUMPTION}

In 1968, Lemoine and colleagues have been the first to describe the situation in which children who presented clinical features of FAS were born from mothers who did not drink but alcoholics fathers [53]. This seems to be the first time that it was introduced the idea that PPAC may have a role in FASD pathogenesis. More than 20 years later, in 1991, Professor Abel found that the response of 
male rats that had consumed alcohol for seven months did not differ significantly from controls in their immobility response in the forced swimming test but, on the other hand, it was the offspring of these males that exhibited a significant dose-related decrease in immobility [54]. These results showed for the first time that, while alcohol's effects may not be observable in males consuming it, this does not necessarily mean that it has no important biological effects on these males and that these effects may not be appreciated until their offspring are examined. This discovery brought new light on the potential role of PPAC in the alcohol disorders-related effects on the offspring. In the years it has been shown how not only the offspring's next generation may be influenced by PPAC, but also multiple generations may be affected, so that the term "transgenerational" may be used to identify the effects of prenatal alcohol exposure on the offspring $[37,49,50]$. Epimutations in the critical genes required for normal development can be transmitted through fertilization and, since only germ cells are in contact with alcohol in the case of PPAC, male sperm has been identified as the main mediator of the toxic effects. Therefore, the transgenerational toxic effects of PPAC are due to alcohol-induced epigenetic mutations in sperm DNA [55-57]. Interestingly, using bisulfite mutagenesis and secondgeneration deep sequencing, no evidence was found that suggested that the alcohol-associated phenotypes and the transcriptional changes are linked to alterations in the sperm-inherited DNA methylation profile emphasizing the importance of epigenetic mechanisms of paternal inheritance beyond DNA methylation [58].

\section{PRECONCEPTUAL ALCOHOL CONSUMPTION IS ASSOCIATED WITH OXIDATIVE STRESS}

Oxidative pathways involve the metabolism of ethanol to acetaldehyde, catalyzed either by alcohol dehydrogenase (ADH), CYP2E1 or catalase [59]. It is currently known how ethanol exposure can lead to the generation of reactive oxygen species (ROS) modifying the intracellular redox state, and ultimately leading to an overall increase in oxidative stress and neuronal cell death by the oxidation of proteins, lipids and DNA [60,61]. In particular, DNA lesions can result in genetic mutations 
involving the DNA sequence of a single cell, resulting in cellular immortalization and clonal expansion ultimately leading to postnatal cancer or, otherwise, it can result in direct or indirect epigenetic modifications to DNA, histones or RNA that involves gene expression of many cells, contributing to teratogenesis in the form of birth defects and postnatal neurodevelopmental abnormalities [59] (Figure 1, point II). Alcohol toxicity is caused both directly by ethanol and indirectly by its metabolic products, including the ROS produced during its biotransformation involving CYP2E1 [62,63]. Interestingly, both maternal and paternal preconceptual alcohol exposure have been related to mitochondrial dysfunction and a significant increase in oxidative stress in developing organs, especially in the central nervous system [64,65]. The relationship between oxidative stress and central nervous system abnormalities should not surprise given that, when compared to other organs, the brain is more susceptible to ROS generation (that include superoxide anions, hydrogen peroxide, and hydroxyl radicals) holding the highest oxygen metabolic rate (its cells utilize $20 \%$ of the oxygen consumed by the entire organism), and brain tissues are rich in unsaturated fatty acids that can be used as substrates for ROS production [66]. Furthermore, some brain regions have a high content of iron and several neurotransmitters tend to spontaneously react with oxygen (namely dopamine, levodopa, serotonin and norepinephrine), which may further promote the generation of ROS [67]. Finally, it should be considered that the activities of the antioxidant enzymes (superoxide dismutase, catalase, and glutathione peroxidase) are lower in the brain than in other organs such as the liver or kidney, while fetal cells are more vulnerable than adult cells to the neurotoxic effects of oxidative stress so that the role of ROS in FASD pathophysiology is clearly of primary importance $[68,69]$. It should be noted that ROS participate in intracellular signaling pathways and that, despite being unstable, are produced naturally in the embryo and fetus and are essential for normal development, so that the problem resides in the imbalance due to excessive ROS production related to the preconceptual alcohol consumption that ultimately causes oxidative stress [70]. Increased activity of the enzyme NADPH oxidase (NOX), which may be the major source of ROS production in the brain, has been related to mouse embryos preconceptual alcohol consumption, 
while co-treatment with the NOX inhibitor (diphenyleneiodonium) has shown to prevent ethanolinduced increases in NOX activity, ROS generation and oxidative DNA damage [64,71-73]. In rodents, antioxidant vitamin E (alpha-tocopherol) increases levels of anti-apoptotic proteins (e.g., Bcl-2, Bcl-xl, activated Akt kinase), downregulates pro-apoptotic proteins (e.g., Bcl-xs), improves organs alterations and DNA damage, and adjusts the level of hyperhomocysteinemia showing promising therapeutic applications in FASD [74-77]. Many other antioxidants have shown, mainly in rodents, promising therapeutic effects: ascorbic acid (vitamin C), beta-carotene, black ginseng, EUK-134 (synthetic superoxide dismutase plus catalase mimetic), folic acid, melatonin, Nacetylcysteine, phenyl butyl nitrone, pycnogenol, silymarin, superoxide dismutase [60,78-85]. Also, the content of antioxidants (polyphenols, resveratrol) in alcoholic beverages (i.e. red wine) may counteract the toxic effect of alcohol per se as shown in FASD/AUD animal models [86-98]. The effects may vary depending on the dose, duration, exposure period and route of exposure for both the ethanol and the antioxidant.

\section{IMPACT OF CHRONIC ALCOHOL USE ON SPERM FUNCTION}

The impact of chronic alcohol use on sperm function and male reproductive physiology has been the center of many studies demonstrating how chronic alcohol consumption has a detrimental impact on male reproductive hormones and semen quality significantly altering the sperm structure and its heritage [99-103]. Furthermore, paternal heavy alcohol consumption, before conception, increases the risk of early pregnancy loss and stillbirth [104,105]. These findings may be considered the pillars that drew attention to the PPAC's role in heritable disorders. Since then, literature expanded and many items employed animal and human models to analyze the relationship between ethanol exposures and the long-term effects on the offspring, highlighting paternally inherited variations in epigenetic coding and their role in numerous disease states of the offspring, including behavior and cognitive alterations, growth deficit, organic and physiological abnormalities related to FASD. 


\section{PATERNAL PRECONCEPTUAL ALCOHOL CONSUMPTION IMPACTS ON THE OFFSPRING BEHAVIOR AND COGNITIVE FUNCTIONS}

In literature, most of the earlier studies about the PPAC role in offspring disorders focused on the behavioral, cognitive and psychological consequences imputable to the impact of the harmful conduct of the fathers [106-109]. It is now factually known that sons of alcoholics when compared to sons of non-alcoholics, may show delayed cognitive performance, increased anxiety and depression, certain neuropsychological deficits in perceptual-motor ability, memory, and language processing as well as auditory and visual attentional impairments, and a lower level of achievement in reading comprehension [110-113]. Furthermore, sons of male alcoholics are at markedly increased genetic risk to develop alcohol abuse and neurotic personality profiles [114-117].

\section{VISUOSPATIAL INFORMATION IMPAIRMENT}

When compared to non-alcoholics, chronic alcoholics and their children show significant deficits in the processing of visuospatial information [118,119]. Sons of active alcoholic, recovering alcoholic, and social drinking fathers tend to perform differently when administered with neuropsychological tests: sons of active alcoholics perform significantly worse on visuospatial, memory, and attentional tasks as well as general intellectual functioning than sons of social drinking fathers and sons of recovering alcoholic fathers (who show no significant difference in their cognitive functioning) [120].

\section{EMOTIONAL RESPONSE}

More recently the altered emotional processing and brain activity in adolescents with familial alcoholism has been deeply analyzed using functional magnetic resonance imaging, showing reduced activity during emotional processing in the superior temporal cortex, as well as during cognitive control within emotional contexts in frontal and striatal regions when compared to adolescents 
without familial alcoholism [121]. Furthermore, reduced resting-state synchrony between the left amygdala and left superior frontal gyrus was related to poorer response inhibition.

As ethanol exposure activates the hypothalamic-pituitary-adrenal axis acting as a physiological stressor, it has been hypothesized that PPAC impacts stress responsivity of offspring [122,123]. This hypothesis seems to be partially confirmed as the studies show ethanol-sired male offspring sexspecific blunted plasma corticosterone levels in response to acute restraint stress, resistance to stressinduced excessive fluid intake, enhanced sensitivity to the anxiolytic and motor-enhancing effects of ethanol, reduced ethanol preference and consumption, altered BDNF (brain-derived neurotrophic factor) and/or NGF (nerve growth factor) (well-known regulators of ethanol drinking behavior $[16,26,117,124-142])$ expression in the ventral tegmental area compared to control-sired male offspring. No differences among ethanol- and control-sired female offspring have been found on these assays. Consistently with the hypothesis of epigenetic effects of PPAC, ethanol exposure also showed to reduce DNA methylation at the BDNF/Promoter of sire's germ cells, while hypomethylation is maintained in the ventral tegmental area of both male and female ethanol-sired offspring [123]. In another study, a voluntary oral route of paternal preconception EtOH exposure, i.e., intermittent every-other-day two-bottle choice drinking, altered offspring behavior [143]. The authors found that paternal preconception every-other-day two-bottle choice drinking resulted in reduced EtOH consumption selectively in male offspring in the drinking in the dark assay compared to control-sired offspring. No differences were detected in either sex in the unlimited access two-bottle choice and elevated plus maze assays. Open field analysis revealed complex changes in basal behavior and EtOH-induced behaviors that were sex specific [143]. All together these studies show that PPAC has persistent effects that impact the next generation.

\section{PATERNAL PRECONCEPTUAL ALCOHOL CONSUMPTION AND NEUROTROPHINS}

Among neurotrophic factors (which regulate cell growth, proliferation, differentiation, and maturation, but also cell migration, metabolism and apoptotic cell death), neurotrophins play a critical 
role in proper brain development, in mediating synaptic plasticity throughout adulthood and in maintaining a balance between neuroendocrine, immune and metabolic systems $[26,144,145]$.

Neurotrophins include NGF, BDNF, neurotrophin-3 (NT-3) and NT-4/5. In particular, NGF and BDNF and their receptors, high-affinity receptor tropomyosin receptor kinase A (TrkA for NGF) and $\mathrm{B}$ (TrkB for BDNF) and low affinity $\mathrm{p} 75$ neurotrophin receptor ( $\mathrm{p} 75^{\mathrm{NTR}}$ for both NGF and BDNF), have been shown to play a crucial role within the pathogenesis of prenatal alcohol exposure since alcohol exposure has been related to neurotrophins alterations in the frontal cortex, striatum and olfactory lobes and disruption of neurotrophin pathways that in turn affects brain cell growth and development and newborns behavior [129,146-150]. More specifically, we found that PPAC induces a higher susceptibility to the ethanol rewarding effects, affecting BDNF in the frontal cortex, striatum and olfactory lobes, TrkA in the hippocampus and $\mathrm{p} 75^{\mathrm{NTR}}$ in the frontal cortex, ultimately inducing ethanol intake preference in the male offspring [129]. Furthermore, alcohol inhibits the expression of the endogenous extracellular signal-regulated kinase (ERK) and the phosphatidylinositol-3-kinase (PI3K) of the neurotrophins pathways [151,152]. Possible links between the epigenetic modulation of NGF and BDNF, the serum levels of interleukin-6 (IL-6) and tumor necrosis factor- $\alpha$ (TNF- $\alpha$ ) and the symptomatology of alcohol dependence have been suggested indicating that changes in the methylation of neurotrophins genes may contribute to the development of alcohol dependence by affecting relevant downstream signaling cascades [151,152].

Modifications in NGF and BDNF levels in the serum and plasma are shown during the onset and progression of many disorders, including neurological, psychiatric and immune diseases $[128,153-$ 164] and during physiopathological conditions as cardiometabolic disruptions [165-169], stressful events [126], aging [169-171] and the post-partum period [127,172]. Recent findings on murine models have analyzed the relationship between PPAC, FASD and neurotrophins alterations suggesting that these proteins could act in a compensatory manner as neuroprotective molecules that can oppose the harmful effects of prenatal alcohol exposure $[173,174]$. 
More recently, we have demonstrated how PPAC may disrupt the epigenetic regulation of postnatal alcohol sensitivity in the offspring by investigating pathways regulating mood, emotion, serotonergic tone and neurotrophins [26,98,117]. In these studies, we demonstrated how PPAC alters the sensitivity to the serotonergic/neurotrophic-associated effects of alcohol affecting the postnatal alcohol preference in the offspring. The analysis of the brainstem gene expression showed serotonin transporter Solute Carrier Family 6 Member 4 (SLC6A4) and low-affinity pan-neurotrophins receptor (p75 NTR) elevation and decreased 5-Hydroxytryptamine Receptor 2C (HTR2C) in the offspring of chronic alcohol-exposed sires [117]. In a different study, male offspring sired by adult male mice exposed to chronic intermittent vapor ethanol before mating showed attenuated ethanol drinking behavior, increased sensitivity to the anxiolytic effects of ethanol, and epigenetic alterations (DNA hypomethylation) and BDNF gene increased expression that persist in the ventral tegmental area [123].

\section{ATTENTION DEFICITS AND HYPERACTIVITY DISORDERS}

Simultaneous preconceptual paternal or maternal exposure to alcohol and environmental tobacco smoke increase the risk of attention deficit hyperactivity disorder (ADHD) diagnosed using the DuPaul Rating Scale [175]. In rats, the presence of a differential effect of amphetamine suggests that the paternal effect on hyperactivity may be mediated by catecholaminergic action [176]. Based on previous experiments which demonstrated how the offspring of male mice chronically exposed to ethanol before mating present attention deficit hyperactivity, altered expression and epigenetic regulation of the dopamine transporter in the frontal cortex, but also altered neurobehavioral outcomes (reflex acquisition, activity, gait) and increased cerebral cortical layer thickness, a recent study demonstrated, in male mice who self-administered $25 \%$ ethanol for an extended period before conception, how PPAC impacts the development of the neocortex and behavior in offspring similarly as previously demonstrated in maternal consumption models of FASD [177-179]. Furthermore, PPAC effects on the offspring may vary with the timing of alcohol exposure relative to conception 
[178]. In fact, it is sufficient 15 to 23 days of PPAC to produce altered behavior at 20 days after birth in a sex-specific manner, including increased activity in males and perturbed sensorimotor integration in both males and females suggesting possible long-lasting, sex-specific effects of PPAC on offspring behavior. In animal models, it has also been shown that one acute dose of alcohol before insemination may cause early developmental delays and behavioral abnormalities such as being less fearful and more aggressive as adults when compared to a control group [180].

\section{COGNITIVE DEFICIT AND MOTOR SKILLS IMPAIRMENT}

Knowing that high levels of paternal and maternal prenatal alcohol exposure are associated with impaired offspring motor development, two recent studies assessed, using the Bayley Scales of Infant Development (BSID-III), the impact of low alcohol consumption before conception on gross motor skills (i.e., coordination of movement using the large muscles of the body) and on cognitive development at 12 -months of age $[181,182]$. The experiments found no evidence that associates low preconceptual alcohol consumption with measurable impairment in infant gross motor skills or cognitive development at 12-months so that further research is needed to examine potential preconceptual alcohol consumption impacts on gross motor skills (and fine motor skills too) and cognitive development in heavier exposure groups especially through the childhood years, when subtle gross motor skills and cognitive deficits may be more easily detectable.

Other findings reported behavioral effects of PPAC on mice offspring are increased immobility in forced swimming tests, decreased grooming, hypoactivity (in contrast to the more often recorded hyperactivity) and failure to initiate and complete the T-maze performance tests (associated with reduced cognitive functioning) [54,115,183,184].

\section{PATERNAL PRECONCEPTUAL ALCOHOL CONSUMPTION IS RELATED TO ORGANIC AND PHYSIOLOGICAL ABNORMALITIES:}

\subsection{Organic Abnormalities}


Higher odds of human microcephaly at birth are associated with higher paternal, but not maternal, alcohol consumption before pregnancy, and similar but weaker effects are estimated for the first drinking trimester [185]. Meanwhile, in mice, it has been demonstrated how PPAC is related to agenesis and skull malformation (exencephaly), as well as the reduced weight of heart, kidney and ventral prostate, causing teratogenic and developmental defects in the next generation at fetal, prenatal and postnatal stages [56].

Male rats consuming alcohol for 8-9 weeks, before conception, produce rat offspring with increased adrenal weights, decreased spleen weights and hypoactivity [186].

\subsection{Hearing Loss}

Data show how chronic PPAC in mice may have a dose-dependent role in offspring's increased hearing loss [187]. In the same study, the authors, also assessed the methylation of H19, Peg3, Ndn and Snrpn in paternal spermatozoa and the cerebral cortices of deaf mice confirming the epigenetic bases of the FASD pathophysiology that have been suggested in previous studies: PPAC alters the methylation of imprinted genes in sire spermatozoa and these genes could be passed on to the offspring ultimately giving rise to developmental disorders [187,188].

\subsection{Neurogenesis, Obesity and Reproductive System Effects}

While most of the experiments have evaluated the effects of prenatal alcohol exposure in the gestational and short term periconceptional period, an interesting study evaluates the effects of adolescent binge alcohol exposure on hypothalamic gene expression patterns in the F1 generation offspring [189]. In this study the authors exposed adolescent male and female rats to a repeated binge EtOH exposure paradigm and then mated them in adulthood. Data showed that the offspring of alcohol-exposed parents had significant differences compared to offspring from alcohol-naïve parents [189]. Specifically, major differences were observed in the expression of genes that mediate neurogenesis and synaptic plasticity during neurodevelopment, genes important for directing chromatin remodeling, post-translational modifications or transcription regulation, as well as genes involved in regulation of obesity and reproductive function [189]. 
There is limited literature on the effects of PPAC on the reproductive development in humans offspring: a recent study that included 1,292 pregnant women shows how paternal alcohol consumption within 3 months before conception may be associated with shorter anogenital distance (the distance from the center of the anus to the genitals) in the newborns, especially in boys [190]. Anogenital distance, which usually persists throughout life, is associated with sperm quality and serum reproductive hormones, it can also predict other androgen-responsive outcomes, such as hypospadias, cryptorchidism and prostate cancer, and so it has an essential role as a sensitive biomarker of reproductive hormone abnormalities during the critical developmental window. These results suggest that paternal alcohol drinking may harm newborns' reproductive development.

\subsection{Endocrine and Immune Alterations}

The proopiomelanocortin (Pomc) gene, that controls neuroendocrine-immune functions has been proven to be imprinted by fetal alcohol exposure. Interestingly, the Pomc gene is hypermethylated through three generations, while the alcohol epigenetic marks on the Pomc gene are maintained in the male but not in the female germline during this transgenerational transmission confirming how the male-specific chromosome is involved in transmitting alcohol epigenetic marks through multiple generations [49].

Another study showed that children with FASD are more susceptible to infections than normal children, and this is also true for children born with PPAC, especially in the case of diseases caused by Pseudomonas aeruginosa [191]. An old, but still actual, article centered on the neurochemical effects of PPAC showed how PPAC causes sex-specific changes in levels of norepinephrine in male offspring, as well as reduced 5-Hydroxytryptamine levels in the cerebrum and increased Metenkephalin levels in all brain regions of offspring from both maternally and paternally exposed rats [192].

\subsection{Reduced Physical Growth, Placental Disruptions and Metabolic Alterations}

Although the first report of an association, in humans, between father's drinking before conception and decreased infant birth weight dates back to 1987, the subsequent findings have been controversial 
for a while, finally demonstrating the importance of the timing, quality and quantity of alcohol exposure in the manifestation of this phenotype $[56,193,194]$. Moreover, only recently the epigenetic mechanisms at the base of this condition are starting to be unraveled.

In literature, mostly using rodents as models, it has been linked chronic PPAC to fetal growth restriction and metabolic alterations [47,195-199].

Knowing that chronic ethanol exposure can affect small non-coding RNA (ncRNAs) abundance and nucleoside modifications in mice sperm and that ncRNAs in sperm have been shown to causally induce heritable phenotypes in the offspring, recently the potential effects of ethanol-responsive sperm ncRNAs on offspring health and development have been investigated $[47,200]$. The findings associated with these studies have been partially related to the growth deficit of the offspring. However, the mechanisms through which the effects of sperm-inherited ncRNAs persist into later life and how the memory of chronic alcohol use transmits to the offspring needs to be further studied. Chronic alcohol consumption alters the sperm constitution at a profound level shifting the proportional ratio of transfer RNA-derived small RNAs to Piwi-interacting RNAs, as well as altered enrichment of microRNAs miR21, miR30, and miR142; interestingly these changes cannot be linked to alcohol-induced changes in the profile of circulating corticosterone but instead may primarily be mediated by effects on epididymal trafficking [47].

Interestingly, as preconceptual alcohol consumption has been demonstrated to reduce global DNA methylation in the developing mouse fetus, in literature it has been specifically examined the effect of PPAC on DNA methylation at H19 imprinting control region (ICR), a paternally methylated ICR in the sperm of exposed males and somatic DNA of sired offspring [55,201,202]. Interestingly, H19 has a role in placental formation and works in combination with Igf2, a potent mitogen, to regulate fetal growth and development. Significant reductions at the H19 CCCTC-binding factors 1 and 2 binding sites were observed in the offspring of ethanol-treated sires and were significantly correlated with reduced weight at postnatal days 35-42 but without affecting birth weight [55]. Furthermore, growth was only delayed during the postnatal weaning period, with subsequent reconvergence, 
suggesting that this transient growth reduction may be the result of a mental deficit that causes the delayed establishment of independent feeding following weaning.

In literature, it has been also emphasized how both the male and female offspring growth restriction associated with PPAC correlates with a reduction in placental efficiency and manifesting mainly during the later phases of pregnancy $[47,58,195]$.

While FASD growth phenotypes can be linked to alcohol-induced intrauterine growth restriction mediated by impaired placentation, it is also true that impaired placentation, in turn, is associated with poor cognitive development and long-term alterations in metabolic programming within the offspring. Additionally, ethanol-impaired placentation has been associated with inhibition of aspartyl(asparaginyl) beta-hydroxylase (AAH) expression, a gene that is regulated by insulin-like growth factors (IGF) and has a critical role in cell motility and invasion, in trophoblasts [203]. Interestingly, it has been suggested a specific pattern of increased placental iodothyronine deiodinase III (Dio3) and decreased thyroid hormone receptor $\alpha 1(\mathrm{TR} \alpha 1)$ and glucocorticoid receptor (GR) protein levels in the placenta as a potential biomarker for intrauterine alcohol exposure [204].

Alcohol-induced growth phenotypes are accompanied in a mouse model by a prolonged period of fetal gestation and sex-specific patterns of postnatal growth restriction characterized by reductions in height, weight, and body mass index that manifest at birth and continue to persist through young adulthood [195].

In rodents, the male offspring of alcohol-exposed fathers continue to exhibit growth deficits in postnatal life, persisting into adolescence, which may be linked to sex-specifically insulin hypersensitivity in the male offspring as well as increased markers of hepatic fibrosis (up-regulation of genes within the pro-fibrotic TGF- $\beta$ signaling pathway), suppressed cytokine profiles within the liver and altered cholesterol trafficking and up-regulation of genes in the LiverX/RetinoidX/FarnesoidX receptor (LRX) pathways (within the liver and pancreas of both the male and female offspring) $[195,196]$. In particular, among liver X receptors (LXR), that regulate many aspects of cholesterol, fatty acid, and glucose homeostasis, and have important roles in 
controlling immune function and neurodevelopment, $\mathrm{LXR} \alpha$ has been identified as a key mediator of male offspring long-term metabolic alterations induced by PPAC being related to resistance to dietinduced obesity and improved glucose homeostasis when challenged with a high-fat diet, as an adaptation mediated by LXR $\alpha$ trans-repression of inflammatory cytokines, following the release of the inhibitor of nuclear factor-kB Kinase $\beta(\operatorname{IKK} \beta)$, related to the insulin signaling pathway. Curiously, paternally programmed increases in LXR $\alpha$ expression seem to be liver-specific and do not manifest in the pancreas or visceral fat.

\subsection{Preconceptual paternal alcohol exposure and sex-specific differences}

Gender differences due to PPAC have been disclosed in animal models. Indeed, PPAC induced a prolonged period of fetal gestation and an increased incidence of intrauterine growth restriction, which affected the male offspring to a greater extent than the females [195]. While the female offspring of ethanol-exposed males were able to match the body weights of the controls within the first 2 weeks of postnatal life, male offspring continued to display an $11 \%$ reduction in weight at 5 weeks of age and a $6 \%$ reduction at 8 weeks of age [195]. The observed growth deficits associated with insulin hypersensitivity in the male offspring, while in contrast, females displayed a modest lag in their glucose tolerance test [195]. These metabolic defects were associated with an up-regulation of genes within the pro-fibrotic TGF- $\beta$ signaling pathway and increased levels of cellular hydroxyproline within the livers of the male offspring [195]. Suppressed cytokine profiles within the liver and pancreas of both the male and female offspring were also observed, which correlated with the up-regulation of genes in the LiverX/RetinoidX/FarnesoidX receptor pathways [195].

In a PPAC chronic intermittent vapor ethanol mouse model [205], authors found that male offspring showed stress hyporesponsivity in a stress-induced hyperthermia assay but female offspring had reduced binge-like ethanol consumption in a drinking in the dark assay compared to control offspring [205]. Another PPAC chronic intermittent vapor ethanol mouse model showed that male offspring exhibited decreased two-bottle free-choice ethanol-drinking preference, increased sensitivity to the anxiolytic effects of ethanol, and increased VTA BDNF expression [116], however, 
no differences were observed in female offspring [116]. In PPAC self-administration mouse model authors discovered that PPAC elicited a sex-specific increase in activity and sensorimotor integration deficits at P20, and decreased balance, coordination, and short-term motor learning at P30 [177] suggesting that PPAC may generate long-lasting, sex-specific effects on offspring behavior. [177].

As for human PPAC studies anecdotal evidence suggests that paternal alcoholism may play an unidentified role in the aetiology of Turner syndrome, a sex chromosome aneuploidy that occurs as a result of a non-disjunctional error in meiosis I or anaphase lag, however, a study suggested there is no association between paternal or maternal alcohol consumption and Turner syndrome [206]. In a study investigating the association between PPAC and anogenital distance [190], authors found that boys had shorter anogenital distance during growth but in girls shorter anogenital distance was observed only at birth [190].

\section{DISCUSSION}

In this narrative review, we have shown how PPAC plays a substantial but underestimated role in FASD pathogenesis. Increasing evidence from a variety of model organisms (mostly mouse) suggests that the environment can affect epigenetic inheritance and that related non-genetically determined phenotypes can be passed between generations with complex and mostly unclear means [207,208]. We have recently exposed how mechanisms controlling the alcohol drinking behavior and the neurobiological sensitivity to alcohol may be due to disrupted epigenetic regulation of pathways regulating mood, emotion and serotonergic states potentially involved in depression and sickness behavior throughout also changes in the expression of neurotrophins as NGF and BDNF [117] (Figure 1, point III). This important link between alcohol and neurotrophins may imply a neuroprotective effect against alcohol of neuropharmacological approaches based on the increase in neurotrophins availability.

As previously observed, the effects of PPAC involve not only the offspring's next generation but, as a result of epimutations in the critical sperm genes required for normal development, multiple 
generations may be affected $[37,49,50]$. Nevertheless, further studies are needed to uncover the mechanisms through which the effects of sperm-inherited ncRNAs persist into later life and how the memory of chronic alcohol use could be transmitted to the offspring $[47,181,200]$.

Most of the clinical studies involving human subjects concern the PPAC role in offspring's behavioral, cognitive and psychological consequences, so that our data provide evidence that sons of alcoholics, when compared to sons of non-alcoholics, may show delayed cognitive performance, abnormal emotional responses, increased genetic risk to develop alcohol abuse and neurotic personality profiles, impairments in perceptual-motor ability, memory, auditory and visuospatial information, and language processing [106,110,112].

The PPAC has also been related to a series of organic and physiological abnormalities: fetal growth restriction; higher odds of human microcephaly, agenesis and skull malformation (exencephaly); the reduced weight of heart, kidney, spleen and ventral prostate; increased hearing loss; shorter anogenital distance; increased adrenal weights; altered neuroendocrine-immune functions; metabolic variations; teratogenic and developmental defects in the next generation at fetal, prenatal and postnatal stages $[47,185-190,196,203]$.

Despite the sizable amount of data presented in this review please note that, in contrast to the data on the role of maternal alcohol consumption in FASD, it should be considered as still scarce, so that other studies are needed to further investigate most of the relationships already related and analyzed for maternal alcoholics and to generate multiple and new lines of evidence.

Limitations: the first limitation of this narrative review is due to the prevalence of studies based on animal models when compared to human clinical studies. This condition suggests that most of the evidence actually available is transposed from animals to humans. Furthermore, most of the included human studies are observational, instead of experimental, due to the severity of the outcome of FASD in the involved subjects. Despite the extensive research, because of the vast literature on this topic, we can't rule out the possibility that some pieces of evidence maybe not included in this review. 
CONCLUSION

Alcohol abuse is a dangerous condition that involves both females and males causing significant dangerous effects not only to their health but also to their offspring's wellbeing. Despite the abundance of evidence on the role of paternal preconceptual alcohol consumption in fetal alcohol spectrum disorders pathogenesis, this topic is still scarcely known among the general population so that it is of primary importance to raise awareness of citizens on the impact of paternal alcohol use disorders on their and their newborn's health. As oxidative stress caused by preconceptual alcohol use has been clearly related to fetal alcohol spectrum disorders, the evidence suggests how antioxidants could be potential candidates for the development of novel therapeutic strategies for the treatment of such neurodevelopmental disorders. The crucial topic of lifelong disabilities induced by paternal preconceptual alcohol consumption and/or gestational alcohol drinking is quite challenging at the individual, societal, and familial levels. Since a nontoxic drinking behavior before pregnancy (for both men and women) during pregnancy and lactation cannot be established the only suggestion for couples planning pregnancies is to completely avoid the consumption of alcoholic beverages.

\section{CONSENT FOR PUBLICATION}

Not applicable.

\section{CONFLICT OF INTEREST}

The authors declare no conflict of interest, financial or otherwise.

\section{ACKNOWLEDGEMENTS}

Declared none.

\section{FUNDING}

None. 


\section{REFERENCES}

[1] Baigent, M. Managing Patients with Dual Diagnosis in Psychiatric Practice. Curr. Opin. Psychiatry 2012, 25 (3), 201-205.

https://doi.org/10.1097/YCO.0b013e3283523d3d.22449766.

[2] Schottenbauer, M. A.; Hommer, D.; Weingartner, H. Memory Deficits among Alcoholics: Performance on a Selective Reminding Task. Aging, Neuropsychol. Cogn. 2007, 14 (5), 505516. https://doi.org/10.1080/13825580600681305.17828626.

[3] Coleman, L. G.; He, J.; Lee, J.; Styner, M.; Crews, F. T. Adolescent Binge Drinking Alters Adult Brain Neurotransmitter Gene Expression, Behavior, Brain Regional Volumes, and Neurochemistry in Mice. Alcohol. Clin. Exp. Res. 2011. https://doi.org/10.1111/j.15300277.2010.01385.x.

[4] Crews, F. T.; Vetreno, R. P. Mechanisms of Neuroimmune Gene Induction in Alcoholism. Psychopharmacology (Berl). 2016, 233 (9), 1543-1557. https://doi.org/10.1007/s00213-0153906-1.25787746.

[5] Ernst, M. Behavioral Predictors of Substance-Use Initiation in Adolescents With and Without Attention-Deficit/Hyperactivity Disorder. Pediatrics 2006, 117 (6), 2030-2039. https://doi.org/10.1542/peds.2005-0704.16740845.

[6] Coriale, G.; Battagliese, G.; Pisciotta, F.; Attilia, M. L.; Porrari, R.; De Rosa, F.; Vitali, M.; Carito, V.; Messina, M. P.; Greco, A.; et al. Behavioral Responses in People Affected by Alcohol Use Disorder and Psychiatric Comorbidity: Correlations with Addiction Severity. Ann. Ist. Super. Sanita 2019, 55 (2), 131-142. https://doi.org/10.4415/ANN_19_02_05.31264636.

[7] Ceci, F. M.; Ceccanti, M.; Petrella, C.; Vitali, M.; Messina, M. P.; Chaldakov, G. N.; Greco, A.; Ralli, M.; Lucarelli, M.; Angeloni, A.; et al. Alcohol Drinking, Apolipoprotein Polymorphisms and the Risk of Cardiovascular Diseases. Curr. Neurovasc. Res. 2021, 18 (1), 150-161. https://doi.org/10.2174/1567202618666210406123503.33823779. 
[8] Ceccanti, M.; Hamilton, D.; Coriale, G.; Carito, V.; Aloe, L.; Chaldakov, G.; Romeo, M.; Ceccanti, M.; Iannitelli, A.; Fiore, M. Spatial Learning in Men Undergoing Alcohol Detoxification. Physiol. Behav. 2015, 149, 324-330.

https://doi.org/10.1016/j.physbeh.2015.06.034.26143187.

[9] Ceccanti, M.; Coriale, G.; Hamilton, D. A.; Carito, V.; Coccurello, R.; Scalese, B.; Ciafrè, S.; Codazzo, C.; Messina, M. P.; Chaldakov, G. N.; et al. Virtual Morris Task Responses in Individuals in an Abstinence Phase from Alcohol. Can. J. Physiol. Pharmacol. 2018, 96 (2), 128-136. https://doi.org/10.1139/cjpp-2017-0013.28763626.

[10] Ceccanti, M.; Iannitelli, A.; Fiore, M. Italian Guidelines for the Treatment of Alcohol Dependence. Riv. Psichiatr. 2018, 53 (3), 105-106.

https://doi.org/10.1708/2925.29410.29912210.

[11] Ernst, C.; Deleva, V.; Deng, X.; Sequeira, A.; Pomarenski, A.; Klempan, T.; Ernst, N.; Quirion, R.; Gratton, A.; Szyf, M.; et al. Alternative Splicing, Methylation State, and Expression Profile of Tropomyosin-Related Kinase B in the Frontal Cortex of Suicide Completers. Arch Gen Psychiatry 2009, 66, 22-32.

[12] Kleiber, M. L.; Laufer, B. I.; Stringer, R. L.; Singh, S. M. Third Trimester-Equivalent Ethanol Exposure Is Characterized by an Acute Cellular Stress Response and an Ontogenetic Disruption of Genes Critical for Synaptic Establishment and Function in Mice. Dev. Neurosci. 2014, 36 (6), 499-519. https://doi.org/10.1159/000365549.25278313.

[13] Laufer, B. I.; Mantha, K.; Kleiber, M. L.; Diehl, E. J.; Addison, S. M. F.; Singh, S. M. LongLasting Alterations to DNA Methylation and NcRNAs Could Underlie the Effects of Fetal Alcohol Exposure in Mice. Dis. Model. Mech. 2013, 6 (4), 977-992. https://doi.org/10.1242/dmm.010975.

[14] Lussier, A. A.; Bodnar, T. S.; Mingay, M.; Morin, A. M.; Hirst, M.; Kobor, M. S.; Weinberg, J. Prenatal Alcohol Exposure: Profiling Developmental DNA Methylation Patterns in Central and Peripheral Tissues. Front. Genet. 2018, 9. https://doi.org/10.3389/fgene.2018.00610. 
[15] Resendiz, M.; Mason, S.; Lo, C.-L.; Zhou, F. C. Epigenetic Regulation of the Neural Transcriptome and Alcohol Interference during Development. Front. Genet. 2014, 5, 285. https://doi.org/10.3389/fgene.2014.00285.

[16] Ciafrè, S.; Ferraguti, G.; Greco, A.; Polimeni, A.; Ralli, M.; Ceci, F. M.; Ceccanti, M.; Fiore, M. Alcohol as an Early Life Stressor: Epigenetics, Metabolic, Neuroendocrine and Neurobehavioral Implications. Neurosci. Biobehav. Rev. 2020, 118, 654-668. https://doi.org/10.1016/j.neubiorev.2020.08.018.32976915.

[17] Ciafrè, S.; Carito, V.; Tirassa, P.; Ferraguti, G.; Attilia, M. L.; Ciolli, P.; Messina, M. P.; Ceccanti, M.; Fiore, M. Ethanol Consumption and Innate Neuroimmunity. Biomed. Rev. 2017, 28, 49-61. https://doi.org/10.14748/bmr.v28.4451.

[18] Ciafre', S.; Carito, V.; Ferraguti, G.; Greco, A.; Chaldakov, G. N. G. N.; Fiore, M.; Ceccanti, M.; Ciafrè, S.; Carito, V.; Ferraguti, G.; et al. How Alcohol Drinking Affects Our Genes: An Epigenetic Point of View. Biochem. Cell Biol. 2019, 97 (4), bcb-2018-0248.

https://doi.org/10.1139/bcb-2018-0248.30412425.

[19] D’Angelo, A.; Ferraguti, G.; Petrella, C.; Greco, A.; Ralli, M.; Vitali, M.; Framarino dei Malatesta, M.; Fiore, M.; Ceccanti, M.; Messina, M. P. Challenges for Midwives’ Healthcare Practice in the next Decade: COVID-19 - Global Climate Changes - Aging and Pregnancy Gestational Alcohol Abuse. Clin. Ter. 2021, 172 (1), 30-36.

https://doi.org/10.7417/CT.2021.2277.33346323.

[20] Glass, L.; Ware, A. L.; Mattson, S. N. Neurobehavioral, Neurologic, and Neuroimaging Characteristics of Fetal Alcohol Spectrum Disorders. Handb. Clin. Neurol. 2014, 125, 435462. https://doi.org/10.1016/B978-0-444-62619-6.00025-2.25307589.

[21] Tunc-Ozcan, E.; Sittig, L. J.; Harper, K. M.; Graf, E. N.; Redei, E. E. Hypothesis: Genetic and Epigenetic Risk Factors Interact to Modulate Vulnerability and Resilience to FASD. Front. Genet. 2014, 5 (AUG). https://doi.org/10.3389/fgene.2014.00261.

[22] Nash, K.; Rovet, J.; Greenbaum, R.; Fantus, E.; Nulman, I.; Koren, G. Identifying the 
Behavioural Phenotype in Fetal Alcohol Spectrum Disorder: Sensitivity, Specificity and Screening Potential. Arch Womens Ment Heal. 2006, 9, 181-186.

[23] Messina, M. P.; D’Angelo, A.; Battagliese, G.; Coriale, G.; Tarani, L.; Pichini, S.; Rasio, D.; Parlapiano, G.; Fiore, M.; Petrella, C.; et al. Fetal Alcohol Spectrum Disorders Awareness in Health Professionals: Implications for Psychiatry. Riv. Psichiatr. 2020, 55 (2), 79-89. https://doi.org/10.1708/3333.33022.32202545.

[24] Coriale, G.; Fiorentino, D.; Lauro, F. D. I.; Marchitelli, R.; Scalese, B.; Fiore, M.; Maviglia, M.; Ceccanti, M. Fetal Alcohol Spectrum Disorder (FASD): Neurobehavioral Profile, Indications for Diagnosis and Treatment. Riv. Psichiatr. 2013, 48 (5), 359-369. https://doi.org/10.1708/1356.15062.

[25] Kodituwakku, P.; Coriale, G.; Fiorentino, D.; Aragón, A. S.; Kalberg, W. O.; Buckley, D.; Gossage, J. P.; Ceccanti, M.; May, P. A. Neurobehavioral Characteristics of Children with Fetal Alcohol Spectrum Disorders in Communities from Italy: Preliminary Results. Alcohol. Clin. Exp. Res. 2006, 30 (9), 1551-1561. https://doi.org/10.1111/j.15300277.2006.00187.x.16930218.

[26] Carito, V.; Ceccanti, M.; Ferraguti, G.; Coccurello, R.; Ciafrè, S.; Tirassa, P.; Fiore, M. NGF and BDNF Alterations by Prenatal Alcohol Exposure. Curr. Neuropharmacol. 2019, 17 (4), 308-317. https://doi.org/10.2174/1570159x15666170825101308.28847297.

[27] Popova, S.; Lange, L.; Probst, C.; Gmel, G.; Rehm, J. Estimation of National, Regional, and Global Prevalence of Alcohol Use during Pregnancy and Fetal Alcohol Syndrome: A Systematic Review and Meta-Analysis. Lancet 2017, 5 (3), 290-299.

[28] Weinberg, N. Z. Cognitive and Behavioral Deficits Associated with Parental Alcohol Use. J. Am. Acad. Child Adolesc. Psychiatry 1997, 36 (9), 1177-1186. https://doi.org/10.1097/00004583-199709000-00009.9291718.

[29] Hoyme, H. E.; Kalberg, W. O.; Elliott, A. J.; Blankenship, J.; Buckley, D.; Marais, A.-S.; Manning, M. A.; Robinson, L. K.; Adam, M. P.; Abdul-Rahman, O.; et al. Updated Clinical 
Guidelines for Diagnosing Fetal Alcohol Spectrum Disorders. Pediatrics 2016, 138 (2), e20154256-e20154256. https://doi.org/10.1542/peds.2015-4256.27464676.

[30] Ferraguti, G.; Ciolli, P.; Carito, V.; Battagliese, G.; Mancinelli, R.; Ciafrè, S.; Tirassa, P.; Ciccarelli, R.; Cipriani, A.; Messina, M. P.; et al. Ethylglucuronide in the Urine as a Marker of Alcohol Consumption during Pregnancy: Comparison with Four Alcohol Screening Questionnaires. Toxicol. Lett. 2017, 275, 49-56.

https://doi.org/10.1016/j.toxlet.2017.04.016.28455000.

[31] Aragón, A. S.; Coriale, G.; Fiorentino, D.; Kalberg, W. O.; Buckley, D.; Phillip Gossage, J.; Ceccanti, M.; Mitchell, E. R.; May, P. A. Neuropsychological Characteristics of Italian Children with Fetal Alcohol Spectrum Disorders. Alcohol. Clin. Exp. Res. 2008, 32 (11), 1909-1919. https://doi.org/10.1111/j.1530-0277.2008.00775.x.18715277.

[32] Fiorentino, D.; Coriale, G.; Spagnolo, P. A.; Prastaro, A.; Attilia, M. L.; Mancinelli, R.; Ceccanti, M. Fetal Alcohol Syndrome Disorders: Experience on the Field. The Lazio Study Preliminary Report. Ann. Ist. Super. Sanita 2006, 42 (1), 53-57.16801726.

[33] Ferraguti, G.; Merlino, L.; Battagliese, G.; Piccioni, M. G.; Barbaro, G.; Carito, V.; Messina, M. P.; Scalese, B.; Coriale, G.; Fiore, M.; et al. Fetus Morphology Changes by SecondTrimester Ultrasound in Pregnant Women Drinking Alcohol. Addict. Biol. 2020, 25 (3). https://doi.org/10.1111/adb.12724.30811093.

[34] May, P. A.; Fiorentino, D.; Phillip Gossage, J.; Kalberg, W. O.; Eugene Hoyme, H.; Robinson, L. K.; Coriale, G.; Jones, K. L.; Del Campo, M.; Tarani, L.; et al. Epidemiology of FASD in a Province in Italy: Prevalence and Characteristics of Children in a Random Sample of Schools. Alcohol. Clin. Exp. Res. 2006, 30 (9), 1562-1575. https://doi.org/10.1111/j.15300277.2006.00188.x.16930219.

[35] Jocelynn L. Cook PhD, Courtney R. Green PhD, Christine M. Lilley PhD, S. M. A. P.; Mary Ellen Baldwin, Albert E. Chudley MD, Julianne L. Conry PhD, N. L. M.; Christine A. Loock MD, Jan Lutke, Bernadene F. Mallon MSW, A. A. M. M.; Valerie K. Temple PhD, T. R. M. 
for the C. F. A. S. D.; Network, R. Fetal Alcohol Spectrum Disorder: A Guideline for Diagnosis across the Lifespan. Cmaj 2016, 188 (3), 191-197.

https://doi.org/10.1503/cmaj.141593.26668194.

[36] Thanh, N. X.; Jonsson, E. Life Expectancy of People with Fetal Alcohol Syndrome. J. Popul. Ther. Clin. Pharmacol. 2016, 23 (1), e53-e59.26962962.

[37] Andrey Finegersh, Gregory R Rompala, David I K Martin, G. E. H. Drinking beyond a Lifetime: New and Emerging Insights into Paternal Alcohol Exposure on Subsequent Generations. Alcohol 2015, 49 (5), 461-470.

https://doi.org/10.1016/j.alcohol.2015.02.008.Drinking.25887183.

[38] Prescott, C. A.; Kendler, K. S. Genetic and Environmental Contributions to Alcohol Abuse and Dependence in a Population-Based Sample of Male Twins. Am. J. Psychiatry 1999, 156 (1), 34-40. https://doi.org/10.1176/ajp.156.1.34.9892295.

[39] Young-Wolff, K. C.; Enoch, M. A.; Prescott, C. A. The Influence of Gene-Environment Interactions on Alcohol Consumption and Alcohol Use Disorders: A Comprehensive Review. Clin. Psychol. Rev. 2011, 31 (5), 800-816. https://doi.org/10.1016/j.cpr.2011.03.005.21530476.

[40] Ystrom, E.; Reichborn-Kjennerud, T.; Aggen, S. H.; Kendler, K. S. Alcohol Dependence in Men: Reliability and Heritability. Alcohol. Clin. Exp. Res. 2011, 35 (9), 1716-1722. https://doi.org/10.1111/j.1530-0277.2011.01518.x.21676009.

[41] Popova, S.; Lange, S.; Shield, K.; Burd, L.; Rehm, J. Prevalence of Fetal Alcohol Spectrum Disorder among Special Subpopulations: A Systematic Review and Meta-Analysis. Addiction 2019, 114 (7), 1150-1172. https://doi.org/10.1111/add.14598.30831001.

[42] Wilhoit, L. F.; Scott, D. A.; Simecka, B. A. Fetal Alcohol Spectrum Disorders: Characteristics, Complications, and Treatment. Community Ment. Health J. 2017, 53 (6), 711-718. https://doi.org/10.1007/s10597-017-0104-0.28168434.

[43] Gupta, K. K.; Gupta, V. K.; Shirasaka, T. An Update on Fetal Alcohol Syndrome- 
Pathogenesis, Risks, and Treatment. Alcohol. Clin. Exp. Res. 2016, 40 (8), 1594-1602. https://doi.org/10.1111/acer.13135.27375266.

[44] Sittig, L. J.; Shukla, P. K.; Herzing, L. B. K.; Redei, E. E. Strain-specific Vulnerability to Alcohol Exposure in Utero via Hippocampal Parent-of-origin Expression of Deiodinase-III . FASEB J. 2011, 25 (7), 2313-2324. https://doi.org/10.1096/fj.10-179234.21429942.

[45] Ledda, R.; Battagliese, G.; Attilia, F.; Rotondo, C.; Pisciotta, F.; Gencarelli, S.; Greco, A.; Fiore, M.; Ceccanti, M.; Attilia, M. L. M. L. Drop-out, Relapse and Abstinence in a Cohort of Alcoholic People under Detoxification. Physiol. Behav. 2019, 198, 67-75. https://doi.org/10.1016/j.physbeh.2018.10.009.30336230.

[46] Rando, O. J.; Simmons, R. A. I'm Eating for Two: Parental Dietary Effects on Offspring Metabolism. Cell. 2015, pp 93-105. https://doi.org/10.1016/j.cell.2015.02.021.25815988.

[47] Bedi, Y.; Chang, R. C.; Gibbs, R.; Clement, T. M.; Golding, M. C. Alterations in SpermInherited Noncoding RNAs Associate with Late-Term Fetal Growth Restriction Induced by Preconception Paternal Alcohol Use. Reprod. Toxicol. 2019, 87 (December 2018), 11-20. https://doi.org/10.1016/j.reprotox.2019.04.006.31051257.

[48] Abel, E. L. Paternal Contribution to Fetal Alcohol Syndrome. Addict. Biol. 2004, 9 (2), $127-$ 133. https://doi.org/10.1080/13556210410001716980.15223537.

[49] Sarkar, D. K. Male Germline Transmits Fetal Alcohol Epigenetic Marks for Multiple Generations: A Review. Addiction Biology. Blackwell Publishing Ltd January 2016, pp 2334. https://doi.org/10.1111/adb.12186.

[50] Rompala, G. R.; Homanics, G. E. Intergenerational Effects of Alcohol: A Review of Paternal Preconception Ethanol Exposure Studies and Epigenetic Mechanisms in the Male Germline. Alcoholism: Clinical and Experimental Research. 2019, pp 1032-1045. https://doi.org/10.1111/acer.14029.30908630.

[51] Schardt, C.; Adams, M. B.; Owens, T.; Keitz, S.; Fontelo, P. Utilization of the PICO Framework to Improve Searching PubMed for Clinical Questions. BMC Med. Inform. Decis. 
Mak. 2007, 7, 1-6. https://doi.org/10.1186/1472-6947-7-16.17573961.

[52] Bilotta, F.; Terracina, S.; Lamperti, M. NIRS - Evidence- or Eminence-Based Practice? Anaesthesia. Blackwell Publishing Ltd July 2018, pp 912-913.

https://doi.org/10.1111/anae.14338.29890002.

[53] Lemoine, P.; Harousseau, H.; Borteyru, J. P.; Menuet, J. C. Children of Alcoholic Parents Observed Anomalies: Discussion of 127 Cases. Ouest Med. Ther Drug Monit April 1968, pp $476-482$.

[54] Abel, E. L. Alcohol Consumption Does Not Affect Fathers but Does Affect Their Offspring in the Forced Swimming Test. Pharmacol. Toxicol. 1991, 68 (1), 68-69. https://doi.org/10.1111/j.1600-0773.1991.tb01211.x.2008415.

[55] Knezovich, J. G.; Ramsay, M. The Effect of Preconception Paternal Alcohol Exposure on Epigenetic Remodeling of the H19 and Rasgrfl Imprinting Control Regions in Mouse Offspring. Front. Genet. 2012, 3 (FEB), 1-10. https://doi.org/10.3389/fgene.2012.00010.

[56] Lee, H. J.; Ryu, J. S.; Choi, N. Y.; Park, Y. S.; Kim, Y. Il; Han, D. W.; Ko, K.; Shin, C. Y.; Hwang, H. S.; Kang, K. S.; et al. Transgenerational Effects of Paternal Alcohol Exposure in Mouse Offspring. Animal Cells Syst. (Seoul). 2013, 17 (6), 429-434. https://doi.org/10.1080/19768354.2013.865675.

[57] Abel, E. L. Paternal and Maternal Alcohol Consumption: Effects on Offspring in Two Strains of Rats. Alcohol. Clin. Exp. Res. 1989, 13 (4), 533-541. https://doi.org/10.1111/j.1530-0277.1989.tb00373.x.

[58] Chang, R. C.; Skiles, W. M.; Chronister, S. S.; Wang, H.; Sutton, G. I.; Bedi, Y. S.; Snyder, M.; Long, C. R.; Golding, M. C. DNA Methylation-Independent Growth Restriction and Altered Developmental Programming in a Mouse Model of Preconception Male Alcohol Exposure. Epigenetics 2017, 12 (10), 841-853. https://doi.org/10.1080/15592294.2017.1363952.28816587.

[59] Bhatia, S.; Drake, D. M.; Miller, L.; Wells, P. G. Oxidative Stress and DNA Damage in the 
Mechanism of Fetal Alcohol Spectrum Disorders. Birth Defects Res. 2019, 111 (12), 714748. https://doi.org/10.1002/bdr2.1509.31033255.

[60] Brocardo, P. S.; Gil-Mohapel, J.; Christie, B. R. The Role of Oxidative Stress in Fetal Alcohol Spectrum Disorders. Brain Res Rev 2011.

[61] Miller-Pinsler, L.; Wells, P. G. Deficient DNA Repair Exacerbates Ethanol-Initiated DNA Oxidation and Embryopathies in Ogg1 Knockout Mice: Gender Risk and Protection by a Free Radical Spin Trapping Agent. Arch. Toxicol. 2016, 90 (2), 415-425. https://doi.org/10.1007/s00204-014-1397-1.25354798.

[62] Halliwell, B. Reactive Species and Antioxidants. Redox Biology Is a Fundamental Theme of Aerobic Life. Plant Physiology. Plant Physiol June 2006, pp 312-322. https://doi.org/10.1104/pp.106.077073.16760481.

[63] Harwell, B. Biochemistry of Oxidative Stress. In Biochemical Society Transactions; Biochem Soc Trans, 2007; Vol. 35, pp 1147-1150. https://doi.org/10.1042/BST0351147.17956298.

[64] Chu, J.; Tong, M.; Monte, S. M. Chronic Ethanol Exposure Causes Mitochondrial Dysfunction and Oxidative Stress in Immature Central Nervous System Neurons. Acta Neuropathol. 2007, 113 (6), 659-673. https://doi.org/10.1007/s00401-007-0199-4.

[65] Wells, P. G.; Bhatia, S.; Drake, D. M.; Miller-Pinsler, L. Fetal Oxidative Stress Mechanisms of Neurodevelopmental Deficits and Exacerbation by Ethanol and Methamphetamine. Birth Defects Res. Part C - Embryo Today Rev. 2016, 108 (2), 108-130. https://doi.org/10.1002/bdrc.21134.27345013.

[66] Sokoloff, L. Energetics of Functional Activation in Neural Tissues. Neurochem. Res. 1999, 24 (2), 321-329. https://doi.org/10.1023/A:1022534709672.9972882.

[67] Gerlach, M.; Ben-Shachar, D.; Riederer, P.; Youdim, M. B. H. Altered Brain Metabolism of Iron as a Cause of Neurodegenerative Diseases? Journal of Neurochemistry. Blackwell Publishing Ltd 1994, pp 793-807. https://doi.org/10.1046/j.1471- 
4159.1994.63030793.x.7519659.

[68] Bergamini, C.; Gambetti, S.; Dondi, A.; Cervellati, C. Oxygen, Reactive Oxygen Species and Tissue Damage. Curr. Pharm. Des. 2005, 10 (14), 1611-1626.

https://doi.org/10.2174/1381612043384664.15134560.

[69] Floyd, R. A.; Carney, J. M. Free Radical Damage to Protein and DNA: Mechanisms Involved and Relevant Observations on Brain Undergoing Oxidative Stress. Ann. Neurol. 1992, 32 (S1), S22-S27. https://doi.org/10.1002/ana.410320706.

[70] Miller, L.; Shapiro, A. M.; Wells, P. G. Embryonic Catalase Protects against EthanolInitiated DNA Oxidation and Teratogenesis in Acatalasemic and Transgenic Human Catalase-Expressing Mice. Toxicol. Sci. 2013, 134 (2), 400-411. https://doi.org/10.1093/toxsci/kft122.23733920.

[71] Dong, J.; Sulik, K. K.; Chen, S. yu. The Role of NOX Enzymes in Ethanol-Induced Oxidative Stress and Apoptosis in Mouse Embryos. Toxicol. Lett. 2010, 193 (1), 94-100. https://doi.org/10.1016/j.toxlet.2009.12.012.

[72] Hill, A. J.; Drever, N.; Yin, H.; Tamayo, E.; Saade, G.; Bytautiene, E. The Role of NADPH Oxidase in a Mouse Model of Fetal Alcohol Syndrome. Am. J. Obstet. Gynecol. 2014, 210 (5), 466.e1-466.e5. https://doi.org/10.1016/j.ajog.2013.12.019.24334207.

[73] Miller-Pinsler, L.; Sharma, A.; Wells, P. G. Enhanced NADPH Oxidases and Reactive Oxygen Species in the Mechanism of Methanol-Initiated Protein Oxidation and Embryopathies in Vivo and in Embryo Culture. Arch. Toxicol. 2016, 90 (3), 717-730. https://doi.org/10.1007/s00204-015-1482-0.25726414.

[74] Heaton, M. B.; Madorsky, I.; Paiva, M.; Siler-Marsiglio, K. I. Vitamin E Amelioration of Ethanol Neurotoxicity Involves Modulation of Apoptotis-Related Protein Levels in Neonatal Rat Cerebellar Granule Cells. Dev. Brain Res. 2004, 150 (2), 117-124. https://doi.org/10.1016/j.devbrainres.2004.03.010.15158075.

[75] Shirpoor, A.; Salami, S.; Khadem-Ansari, M. H.; Minassian, S.; Yegiazarian, M. Protective 
Effect of Vitamin e against Ethanol-Induced Hyperhomocysteinemia, DNA Damage, and Atrophy in the Developing Male Rat Brain. Alcohol. Clin. Exp. Res. 2009, 33 (7), 11811186. https://doi.org/10.1111/j.1530-0277.2009.00941.x.19389196.

[76] Marino, M. D.; Aksenov, M. Y.; Kelly, S. J. Vitamin E Protects against Alcohol-Induced Cell Loss and Oxidative Stress in the Neonatal Rat Hippocampus. Int. J. Dev. Neurosci. 2004, 22 (5-6), 363-377. https://doi.org/10.1016/j.ijdevneu.2004.04.005.15380836.

[77] Wentzel, P.; Rydberg, U.; Eriksson, U. J. Antioxidative Treatment Diminishes EthanolInduced Congenital Malformations in the Rat. Alcohol. Clin. Exp. Res. 2006, 30 (10), 17521760. https://doi.org/10.1111/j.1530-0277.2006.00208.x.17010142.

[78] Cano, M. J.; Ayala, A.; Murillo, M. L.; Carreras, O. Protective Effect of Folic Acid against Oxidative Stress Produced in 21-Day Postpartum Rats by Maternal-Ethanol Chronic Consumption during Pregnancy and Lactation Period. Free Radic. Res. 2001, 34 (1), 1-8. https://doi.org/10.1080/10715760100300011.11234991.

[79] Chen, S.; Dehart, D. B.; Sulik, K. K. Protection from Ethanol-induced Limb Malformations by the Superoxide Dismutase/Catalase Mimetic, EUK-134. FASEB J. 2004, 18 (11), 1234 1236. https://doi.org/10.1096/fj.03-0850fje.15208273.

[80] Lee, S. R.; Kim, M. R.; Yon, J. M.; Baek, I. J.; Park, C. G.; Lee, B. J.; Yun, Y. W.; Nam, S. Y. Black Ginseng Inhibits Ethanol-Induced Teratogenesis in Cultured Mouse Embryos through Its Effects on Antioxidant Activity. Toxicol. Vitr. 2009, 23 (1), 47-52. https://doi.org/10.1016/j.tiv.2008.10.001.18992320.

[81] Mitchell, J. J.; Paiva, M.; Heaton, M. B. The Antioxidants Vitamin e and $\beta$-Carotene Protect against Ethanol- Induced Neurotoxicity in Embryonic Rat Hippocampal Cultures. Alcohol 1999, 17 (2), 163-168. https://doi.org/10.1016/S0741-8329(98)00051-2.10064385.

[82] Peng, Y.; Kwok, K. H. H.; Yang, P. H.; Ng, S. S. M.; Liu, J.; Wong, O. G.; He, M. L.; Kung, H. F.; Lin, M. C. M. Ascorbic Acid Inhibits ROS Production, NF-KB Activation and Prevents Ethanol-Induced Growth Retardation and Microencephaly. Neuropharmacology 
2005, 48 (3), 426-434. https://doi.org/10.1016/j.neuropharm.2004.10.018.15721175.

[83] Siler-Marsiglio, K. I.; Shaw, G.; Heaton, M. B. Pycnogenol ${ }^{\circledR}$ and Vitamin E Inhibit EthanolInduced Apoptosis in Rat Cerebellar Granule Cells. J. Neurobiol. 2004, 59 (3), 261-271. https://doi.org/10.1002/neu.10311.15146544.

[84] Miller, L.; Shapiro, A. M.; Cheng, J.; Wells, P. G. The Free Radical Spin Trapping Agent Phenylbutylnitrone Reduces Fetal Brain DNA Oxidation and Postnatal Cognitive Deficits Caused by in Utero Exposure to a Non-Structurally Teratogenic Dose of Ethanol: A Role for Oxidative Stress. Free Radic. Biol. Med. 2013, 60, 223-232.

https://doi.org/10.1016/j.freeradbiomed.2013.02.015.23485582.

[85] Miller-Pinsler, L.; Wells, P. G. Embryonic Catalase Protects against Ethanol Embryopathies in Acatalasemic Mice and Transgenic Human Catalase-Expressing Mice in Embryo Culture. Toxicol. Appl. Pharmacol. 2015, 287 (3), 232-239. https://doi.org/10.1016/j.taap.2015.06.007.26074427.

[86] Carito, V.; Venditti, A.; Bianco, A.; Ceccanti, M.; Serrilli, A. M.; Chaldakov, G.; Tarani, L.; De Nicolò, S.; Fiore, M. Effects of Olive Leaf Polyphenols on Male Mouse Brain NGF, BDNF and Their Receptors TrkA, TrkB and P75. Nat. Prod. Res. 2014, 28 (22), 1970-1984. https://doi.org/10.1080/14786419.2014.918977.24865115.

[87] Carito, V.; Ceccanti, M.; Tarani, L.; Ferraguti, G.; N. Chaldakov, G.; Fiore, M. Neurotrophins' Modulation by Olive Polyphenols. Curr. Med. Chem. 2016, 23 (28), 31893197. https://doi.org/10.2174/0929867323666160627104022.27356540.

[88] Petrella, C.; Carito, V.; Carere, C.; Ferraguti, G.; Ciafrè, S.; Natella, F.; Bello, C.; Greco, A.; Ralli, M.; Mancinelli, R.; et al. Oxidative Stress Inhibition by Resveratrol in AlcoholDependent Mice. Nutrition 2020, 79-80, 110783. https://doi.org/10.1016/j.nut.2020.110783.32569950.

[89] Carito, V.; Ceccanti, M.; Cestari, V.; Natella, F.; Bello, C.; Coccurello, R.; Mancinelli, R.; Fiore, M. Olive Polyphenol Effects in a Mouse Model of Chronic Ethanol Addiction. 
Nutrition 2017, 33, 65-69. https://doi.org/10.1016/j.nut.2016.08.014.27908553.

[90] Ceccanti, M.; Valentina, C.; Vitali, M.; Iannuzzi, S.; Tarani, L.; De Nicolo, S.; Ceccanti, M. M.; Ciafre, S.; Tirassa, P.; Capriglione, I.; et al. Serum BDNF and NGF Modulation by Olive Polyphenols in Alcoholics during Withdrawal. J. Alcohol. Drug Depend. 2015, 03 (04). https://doi.org/10.4172/2329-6488.1000214.

[91] Chianese, R.; Coccurello, R.; Viggiano, A.; Scafuro, M.; Fiore, M.; Coppola, G.; Operto, F. F.; Fasano, S.; Laye, S.; Pierantoni, R.; et al. Impact of Dietary Fats on Brain Functions. Curr. Neuropharmacol. 2017, 16 (7), 1059-1085. https://doi.org/10.2174/1570159x15666171017102547.29046155.

[92] Fiore, M.; Messina, M. P.; Petrella, C.; D’Angelo, A.; Greco, A.; Ralli, M.; Ferraguti, G.; Tarani, L.; Vitali, M.; Ceccanti, M. Antioxidant Properties of Plant Polyphenols in the Counteraction of Alcohol-Abuse Induced Damage: Impact on the Mediterranean Diet. $J$. Funct. Foods 2020, 71, 104012. https://doi.org/10.1016/j.jff.2020.104012.

[93] Ceccanti, M.; De Nicolò, S.; Mancinelli, R.; Chaldakov, G.; Carito, V.; Ceccanti, M.; Laviola, G.; Tirassa, P.; Fiore, M. NGF and BDNF Long-Term Variations in the Thyroid, Testis and Adrenal Glands of a Mouse Model of Fetal Alcohol Spectrum Disorders. Ann. Ist. Super. Sanita 2013, 49 (4), 383-390. https://doi.org/10.4415/ANN-13-04-11.24334784.

[94] Solfrizzi, V.; Capurso, C.; D’Introno, A.; Colacicco, A. M.; Santamato, A.; Ranieri, M.; Fiore, P.; Capurso, A.; Panza, F. Lifestyle-Related Factors in Predementia and Dementia Syndromes. Expert Rev. Neurother. 2008, 8 (1), 133-158. https://doi.org/10.1586/14737175.8.1.133.18088206.

[95] De Nicolò, S.; Carito, V.; Fiore, M.; Laviola, G. Aberrant Behavioral and Neurobiologic Profiles in Rodents Exposed to Ethanol or Red Wine Early in Development. Curr. Dev. Disord. Reports 2014, 1 (3), 173-180. https://doi.org/10.1007/s40474-014-0023-5.

[96] Fiore, M.; Mancinelli, R.; Aloe, L.; Laviola, G.; Sornelli, F.; Vitali, M.; Ceccanti, M. Hepatocyte Growth Factor, Vascular Endothelial Growth Factor, Glial Cell-Derived 
Neurotrophic Factor and Nerve Growth Factor Are Differentially Affected by Early Chronic Ethanol or Red Wine Intake. Toxicol. Lett. 2009, 188 (3), 208-213.

https://doi.org/10.1016/j.toxlet.2009.04.013.19397965.

[97] Ceccanti, M.; Mancinelli, R.; Tirassa, P.; Laviola, G.; Rossi, S.; Romeo, M.; Fiore, M. Early Exposure to Ethanol or Red Wine and Long-Lasting Effects in Aged Mice. A Study on Nerve Growth Factor, Brain-Derived Neurotrophic Factor, Hepatocyte Growth Factor, and Vascular Endothelial Growth Factor. Neurobiol. Aging 2012, 33 (2), 359-367.

https://doi.org/10.1016/j.neurobiolaging.2010.03.005.20382450.

[98] Fiore, M.; Laviola, G.; Aloe, L.; di Fausto, V.; Mancinelli, R.; Ceccanti, M. Early Exposure to Ethanol but Not Red Wine at the Same Alcohol Concentration Induces Behavioral and Brain Neurotrophin Alterations in Young and Adult Mice. Neurotoxicology 2009, 30 (1), 5971. https://doi.org/10.1016/j.neuro.2008.11.009.19100286.

[99] Anderson, R. A.; Willis, B. R.; Oswald, C.; Reddy, J. M.; Beyler, S. A.; Zaneveld, L. J. D. Hormonal Imbalance and Alterations in Testicular Morphology Induced by Chronic Ingestion of Ethanol. Biochem. Pharmacol. 1980, 29 (10), 1409-1419. https://doi.org/10.1016/0006-2952(80)90437-2.7190392.

[100] Condorelli, R. A.; Calogero, A. E.; Vicari, E.; La Vignera, S. Chronic Consumption of Alcohol and Sperm Parameters: Our Experience and the Main Evidences. Andrologia 2015, 47 (4), 368-379. https://doi.org/10.1111/and.12284.24766499.

[101] Emanuele, N. V.; Lapaglia, N.; Benefield, J.; Emanuele, M. A. Ethanolinduced Hypogonadism Is Not Dependent on Activation of the Hypothalamic-Pituitary-Adrenal Axis. Endocr. Res. 2001, 27 (4), 465-472. https://doi.org/10.1081/ERC-100107869.11794469.

[102] Muthusami, K. R.; Chinnaswamy, P. Effect of Chronic Alcoholism on Male Fertility Hormones and Semen Quality. Fertil. Steril. 2005, 84 (4), 919-924. https://doi.org/10.1016/j.fertnstert.2005.04.025.16213844.

[103] Emanuele, N. V.; LaPaglia, N.; Steiner, J.; Colantoni, A.; Van Thiel, D. H.; Emanuele, M. A. 
Peripubertal Paternal EtOH Exposure: Testicular Oxidative Injury, Fecundity, and Offspring. Endocrine 2001, 14 (2), 213-219. https://doi.org/10.1385/ENDO:14:2:213.11394639.

[104] Henriksen, T. B.; Hjollund, N. H.; Jensen, T. K.; Bonde, J. P.; Andersson, A. M.; Kolstad, H.; Ernst, E.; Giwercman, A.; Skakkebæk, N. E.; Olsen, J. Alcohol Consumption at the Time of Conception and Spontaneous Abortion. Am. J. Epidemiol. 2004, 160 (7), 661-667. https://doi.org/10.1093/aje/kwh259.15383410.

[105] Klonoff-Cohen, H.; Lam-Kruglick, P.; Gonzalez, C. Effects of Maternal and Paternal Alcohol Consumption on the Success Rates of in Vitro Fertilization and Gamete Intrafallopian Transfer. Fertil. Steril. 2003, 79 (2), 330-339. https://doi.org/10.1016/S00150282(02)04582-X.12568842.

[106] Aronson, H.; Gilbert, A. Preadolescent Sons of Male Alcoholics. Arch. Gen. Psychiatry 1963, 28, 238-243.

[107] Bonassi, E.; Sperone, B.; Travisio, A. Paternal Alcoholism as a Risk Factor I the PsychoEffective Development of the Child. Minerva Pediatr. 1974, 26, 1801-1809.

[108] Ervin, C. S.; Little, R. E.; Streissguth, A. P.; Beck, D. E. Alcoholic Fathering and Its Relation to Child's Intellectual Development: A Pilot Investigation. Alcohol. Clin. Exp. Res. 1984, 8 (4), 362-365. https://doi.org/10.1111/j.1530-0277.1984.tb05681.x.6385758.

[109] Abel, E. L.; Lee, J. A. Paternal Alcohol Exposure Affects Offspring Behavior but Not Body or Organ Weights in Mice. Alcohol. Clin. Exp. Res. 1988, 12 (3), 349-355. https://doi.org/10.1111/j.1530-0277.1988.tb00205.x.3044161.

[110] Tarter, R. E.; Hegedus, A. M.; Goldstein, G.; Shelly, C.; Alterman, A. I. Adolescent Sons of Alcoholics: Neuropsychological and Personality Characteristics. Alcohol. Clin. Exp. Res. 1984, 8 (2), 216-222. https://doi.org/10.1111/j.1530-0277.1984.tb05842.x.6375434.

[111] Gabrielli, W. F.; Mednick, S. A. Intellectual Performance in Children of Alcoholics. J. Nerv. Ment. Dis. 1983, 171 (7), 444-447. https://doi.org/10.1097/00005053-19830700000009.6864203 
[112] Hegedus, A. M.; Alterman, A. I.; Tarter, R. E. Learning Achievement in Sons of Alcoholics. Alcohol. Clin. Exp. Res. 1984, 8 (3), 330-333. https://doi.org/10.1111/j.15300277.1984.tb05522.x.6377954.

[113] Ledig, M.; Misslin, R.; Vogel, E.; Holownia, A.; Copin, J. C.; Tholey, G. Paternal Alcohol Exposure: Developmental and Behavioral Effects on the Offspring of Rats.

Neuropharmacology 1998, 37 (1), 57-66. https://doi.org/10.1016/S0028-3908(97)001858.9680259 .

[114] Pihl, R. O.; Peterson, J.; Finn, P. R. Inherited Predisposition to Alcoholism: Characteristics of Sons of Male Alcoholics. J. Abnorm. Psychol. 1990, 99 (3), 291-301. https://doi.org/10.1037//0021-843x.99.3.291.

[115] Hollander, J.; McNivens, M.; Pautassi, R. M.; Nizhnikov, M. E. Offspring of Male Rats Exposed to Binge Alcohol Exhibit Heightened Ethanol Intake at Infancy and Alterations in T-Maze Performance. Alcohol 2019, 76 (203), 65-71.

https://doi.org/10.1016/j.alcohol.2018.07.013.30583252.

[116] Rompala, G. R.; Finegersh, A.; Slater, M.; Homanics, G. E. Paternal Preconception Alcohol Exposure Imparts Intergenerational Alcohol-Related Behaviors to Male Offspring on a Pure C57BL/6J Background. Alcohol 2017, 60, 169-177. https://doi.org/10.1016/j.alcohol.2016.11.001.27876231.

[117] Ferraguti, G.; Codazzo, C.; Petrella, C.; Coccurello, R.; Ceccanti, M.; Fiore, M. Brainstem Expression of SLC6A4, HTR2C, NGF, BDNF, TRKANGF, TRKBBDNF and P75NTR Following Paternal Alcohol Exposure in the Male Mouse. Biomed. Rev. 2020, 31, 75-89. https://doi.org/10.14748/bmr.v31.7707.

[118] Martellucci, S.; Ralli, M.; Attanasio, G.; Russo, F. Y.; Marcelli, V.; Greco, A.; Gallo, A.; Fiore, M.; Petrella, C.; Ferraguti, G.; et al. Alcohol Binge-Drinking Damage on the Vestibulo-Oculomotor Reflex. Eur. Arch. Oto-Rhino-Laryngology 2021, 278 (1), 41-48. https://doi.org/10.1007/s00405-020-06052-1.32449024. 
[119] Schandler, S. L.; Thomas, C. S.; Cohen, M. J. Spatial Learning Deficits in Preschool Children of Alcoholics. Alcohol. Clin. Exp. Res. 1995, 19 (4), 1067-1072. https://doi.org/10.1111/j.1530-0277.1995.tb00990.x.7485818.

[120] Ozkaragoz, T.; Satz, P.; Noble, E. P. Neuropsychological Functioning in Sons of Active Alcoholic, Recovering Alcoholic, and Social Drinking Fathers. Alcohol 1997, 14 (1), 31-37. https://doi.org/10.1016/S0741-8329(96)00084-5.9014021.

[121] Cservenka, A.; Fair, D. A.; Nagel, B. J. Emotional Processing and Brain Activity in Youth at High Risk for Alcoholism. Alcohol. Clin. Exp. Res. 2014, 38 (7), 1912-1923. https://doi.org/10.1111/acer.12435.24890898.

[122] Rompala, G. R.; Finegersh, A.; Homanics, G. E. Paternal Preconception Ethanol Exposure Blunts Hypothalamic-Pituitary-Adrenal Axis Responsivity and Stress-Induced Excessive Fluid Intake in Male Mice. Alcohol 2016, 53, 19-25. https://doi.org/10.1016/j.alcohol.2016.03.006.

[123] Finegersh, A.; Homanics, G. E. Paternal Alcohol Exposure Reduces Alcohol Drinking and Increases Behavioral Sensitivity to Alcohol Selectively in Male Offspring. PLoS One 2014, 9, e99078. https://doi.org/10.1371/journal.pone.0099078.

[124] Aloe, L. Alcohol Intake during Prenatal Life Affects Neuroimmune Mediators and Brain Neurogenesis. Ann. Ist. Super. Sanita 2006, 42 (1), 17-21.16801721.

[125] Ciafrè, S.; Ferraguti, G.; Tirassa, P.; Iannitelli, A.; Ralli, M.; Greco, A.; Chaldakov, G. N. G. N.; Rosso, P.; Fico, E.; Messina, M. P. M. P.; et al. Nerve Growth Factor in the Psychiatric Brain. Riv. Psichiatr. 2020, 55 (1), 4-15. https://doi.org/10.1708/3301.32713.32051620.

[126] Ceci, F. M.; Ferraguti, G.; Petrella, C.; Greco, A.; Tirassa, P.; Iannitelli, A.; Ralli, M.; Vitali, M.; Ceccanti, M.; Chaldakov, G. N.; et al. Nerve Growth Factor, Stress and Diseases. Curr. Med. Chem. 2020, 28 (15), 2943-2959. https://doi.org/10.2174/0929867327999200818111654.32811396.

[127] D’Angelo, A.; Ceccanti, M.; Petrella, C.; Greco, A.; Tirassa, P.; Rosso, P.; Ralli, M.; 
Ferraguti, G.; Fiore, M.; Messina, M. P. M. P. Role of Neurotrophins in Pregnancy, Delivery and Postpartum. Eur. J. Obstet. Gynecol. Reprod. Biol. 2020, 247, 32-41. https://doi.org/10.1016/j.ejogrb.2020.01.046.32058187.

[128] Ceci, F. M.; Ferraguti, G.; Petrella, C.; Greco, A.; Ralli, M.; Iannitelli, A.; Carito, V.; Tirassa, P.; Chaldakov, G. N.; Messina, M. P.; et al. Nerve Growth Factor in Alcohol Use Disorders. Curr. Neuropharmacol. 2020, 19 (1), 45-60. https://doi.org/10.2174/1570159x18666200429003239.32348226.

[129] Ceccanti, M.; Coccurello, R.; Carito, V.; Ciafrè, S.; Ferraguti, G.; Giacovazzo, G.; Mancinelli, R.; Tirassa, P.; Chaldakov, G. N.; Pascale, E.; et al. Paternal Alcohol Exposure in Mice Alters Brain NGF and BDNF and Increases Ethanol-Elicited Preference in Male Offspring. Addict. Biol. 2016, 21 (4), 776-787. https://doi.org/10.1111/adb.12255.25940002.

[130] Heaton, M. B.; Paiva, M.; Madorsky, I.; Shaw, G. Ethanol Effects on Neonatal Rat Cortex: Comparative Analyses of Neurotrophic Factors, Apoptosis-Related Proteins, and Oxidative Processes during Vulnerable and Resistant Periods. Dev. Brain Res. 2003, 145 (2), 249-262. https://doi.org/10.1016/j.devbrainres.2003.08.005.14604765.

[131] Heaton, M. B.; Paiva, M.; Madorsky, I.; Mayer, J.; Moore, D. B. Effects of Ethanol on Neurotrophic Factors, Apoptosis-Related Proteins, Endogenous Antioxidants, and Reactive Oxygen Species in Neonatal Striatum: Relationship to Periods of Vulnerability. Dev. Brain Res. 2003, 140 (2), 237-252. https://doi.org/10.1016/S0165-3806(02)00610-7.12586429.

[132] Davis, M. I. Ethanol-BDNF Interactions: Still More Questions than Answers. Pharmacol Ther 2008, 118, 36-57.

[133] Huang, M. C.; Chen, C. H.; Chen, C. H.; Liu, S. C.; Ho, C. J.; Shen, W. W.; Leu, S. J. Alterations of Serum Brain-Derived Neurotrophic Factor Levels in Early Alcohol Withdrawal. Alcohol Alcohol 2008, 43, 241-245.

[134] Benzerouk, F.; Gierski, F.; Gorwood, P.; Ramoz, N.; Stefaniak, N.; Hübsch, B.; Kaladjian, A.; Limosin, F. Brain-Derived Neurotrophic Factor (BDNF) Val66Met Polymorphism and 
Its Implication in Executive Functions in Adult Offspring of Alcohol-Dependent Probands. Alcohol 2013, 47 (4), 271-274. https://doi.org/10.1016/j.alcohol.2013.03.001.23582695.

[135] Popova, N. K.; Ilchibaeva, T. V.; Antonov, E. V.; Pershina, A. V.; Bazovkina, D. V.; Naumenko, V. S. On the Interaction between BDNF and Serotonin Systems: The Effects of Long-Term Ethanol Consumption in Mice. Alcohol 2020, 87, 1-15. https://doi.org/10.1016/j.alcohol.2020.04.002.32330588.

[136] Manni, L.; Aloe, L.; Fiore, M. Changes in Cognition Induced by Social Isolation in the Mouse Are Restored by Electro-Acupuncture. Physiol. Behav. 2009, 98 (5), 537-542. https://doi.org/10.1016/j.physbeh.2009.08.011.19733189.

[137] Tarani, L.; Carito, V.; Ferraguti, G.; Petrella, C.; Greco, A.; Ralli, M.; Messina, M. P.; Rasio, D.; De Luca, E.; Putotto, C.; et al. Neuroinflammatory Markers in the Serum of Prepubertal Children with down Syndrome. J. Immunol. Res. 2020, 2020, 6937154. https://doi.org/10.1155/2020/6937154.32280719.

[138] Pacitti, F.; Bersani, G.; Aloe, L.; Caredda, M.; Orsi, P.; Quartini, A.; Vitali, M.; Ceccanti, M.; Tirassa, P.; Fiore, M.; et al. Nerve Growth Factor Serum Levels in Treatment-Resistant Schizophrenic Patients Following Electroconvulsive Therapy. Clin. Ter. 2021, 171 (1), e67e74. https://doi.org/10.7417/CT.2021.2286.33346332.

[139] De Simone, R.; Aloe, L. Influence of Ethanol Consumption on Brain Nerve Growth Factor and Its Target Cells in Developing and Adult Rodents. Ann. Ist. Super. Sanita 1993, 29 (1), $179-183.8129266$.

[140] Caroleo, M. C.; Costa, N.; Tirassa, P.; Aloe, L. Nerve Growth Factor Produced by Activated Human Monocytes/Macrophages Is Severely Affected by Ethanol. Alcohol 2004, 34, 107114. https://doi.org/10.1016/j.alcohol.2004.06.005.

[141] Angelucci, F.; Fiore, M.; Cozzari, C.; Aloe, L. Prenatal Ethanol Effects on NGF Level, NPY and ChAT Immunoreactivity in Mouse Entorhinal Cortex: A Preliminary Study.

Neurotoxicol. Teratol. 1999, 21 (4), 415-425. https://doi.org/10.1016/S0892-0362(99)00005- 
7.10440485.

[142] Aloe, L.; Tirassa, P. The Effect of Long-Term Alcohol Intake on Brain Ngf-Target Cells of Aged Rats. Alcohol 1992, 9 (4), 299-304. https://doi.org/10.1016/0741-8329(92)90070q. 1322141.

[143] Beeler, E.; Nobile, Z. L.; Homanics, G. E. Paternal Preconception Every-Other-Day Ethanol Drinking Alters Behavior and Ethanol Consumption in Offspring. Brain Sci. 2019, 9 (3). https://doi.org/10.3390/brainsci9030056.30845665.

[144] Levi-Montalcini, R. The Nerve Growth Factor 35 Years Later. Science (80-. ). 1987, 237 (4819), 1154-1162. https://doi.org/10.1126/science.3306916.3306916.

[145] Barde, Y. A. Neurotrophic Factors: An Evolutionary Perspective. J Neurobiol 1994, 25, 1329-33.

[146] Fiore, M.; Korf, J.; Angelucci, F.; Talamini, L.; Aloe, L. Prenatal Exposure to Methylazoxymethanol Acetate in the Rat Alters Neurotrophin Levels and Behavior: Considerations for Neurodevelopmental Diseases. Physiol. Behav. 2000, 71 (1-2), 57-67. https://doi.org/10.1016/S0031-9384(00)00310-3.11134686.

[147] Fiore, M.; Korf, J.; Antonelli, A.; Talamini, L.; Aloe, L. Long-Lasting Effects of Prenatal MAM Treatment on Water Maze Performance in Rats: Associations with Altered Brain Development and Neurotrophin Levels. Neurotoxicol. Teratol. 2002, 24 (2), 179-191. https://doi.org/10.1016/S0892-0362(01)00214-8.11943506.

[148] Angelucci, F.; Piermaria, J.; Gelfo, F.; Shofany, J.; Tramontano, M.; Fiore, M.; Caltagirone, C.; Peppe, A. The Effects of Motor Rehabilitation Training on Clinical Symptoms and Serum BDNF Levels in Parkinson's Disease Subjects. Can. J. Physiol. Pharmacol. 2016, 94 (4), 455-461. https://doi.org/10.1139/cjpp-2015-0322.26863448.

[149] Angelucci, F.; Cimino, M.; Balduini, W.; Piltillo, L.; Aloe, L. Prenatal Exposure to Ethanol Causes Differential Effects in Nerve Growth Factor and Its Receptor in the Basal Forebrain of Preweaning and Adult Rats. J Neural Transplant. Plast 1997, 6 (2), 63-71. 
https://doi.org/10.1155/NP.1997.63.9306238.

[150] Fiore, M.; Chaldakov, G. N.; Aloe, L. Nerve Growth Factor as a Signaling Molecule for Nerve Cells and Also for the Neuroendocrine-Immune Systems. Rev. Neurosci. 2009, 20 (2), 133-145. https://doi.org/10.1515/REVNEURO.2009.20.2.133.19774790.

[151] Li, Z.; Ding, M.; Thiele, C. J.; Luo, J. Ethanol Inhibits Brain-Derived Neurotrophic FactorMediated Intracellular Signaling and Activator Protein-1 Activation in Cerebellar Granule Neurons. Neuroscience 2004, 126 (1), 149-162. https://doi.org/10.1016/j.neuroscience.2004.03.028.15145081.

[152] Heberlein, A.; Schuster, R.; Kleimann, A.; Groh, A.; Kordon, A.; Opfermann, B.; Lichtinghagen, R.; Gröschl, M.; Kornhuber, J.; Bleich, S.; et al. Joint Effects of the Epigenetic Alteration of Neurotrophins and Cytokine Signaling: A Possible Exploratory Model of Affective Symptoms in Alcohol-Dependent Patients? Alcohol Alcohol 2017, 52 (3), 277-281. https://doi.org/10.1093/alcalc/agw100.

[153] Amendola, T.; Fiore, M.; Aloe, L. Postnatal Changes in Nerve Growth Factor and Brain Derived Neurotrophic Factor Levels in the Retina, Visual Cortex, and Geniculate Nucleus in Rats with Retinitis Pigmentosa. Neurosci. Lett. 2003, 345 (1), 37-40. https://doi.org/10.1016/S0304-3940(03)00491-9.

[154] Schulte-Herbruggen, O.; Braun, A.; Rochlitzer, S.; Jockers-Scherubl, M. C.; Hellweg, R. Neurotrophic Factors--a Tool for Therapeutic Strategies in Neurological, Neuropsychiatric and Neuroimmunological Diseases? Curr Med Chem 2007, 14, 2318-2329.

[155] Tirassa, P.; Rosso, P.; Iannitelli, A. Ocular Nerve Growth Factor (NGF) and NGF Eye Drop Application as Paradigms to Investigate NGF Neuroprotective and Reparative Actions. In Methods in Molecular Biology; 2018; Vol. 1727, pp 19-38. https://doi.org/10.1007/978-14939-7571-6_2.29222770.

[156] Aloe, L.; Skaper, S. D.; Leon, A.; Levi-Montalcini, R. Nerve Growth Factor and Autoimmune Diseases. Autoimmunity 1994, 19 (2), 141-150. 
https://doi.org/10.3109/08916939409009542.7772704.

[157] Bersani, G.; Iannitelli, A.; Fiore, M.; Angelucci, F.; Aloe, L. Data and Hypotheses on the Role of Nerve Growth Factor and Other Neurotrophins in Psychiatric Disorders. Med. Hypotheses 2000, 55 (3), 199-207. https://doi.org/10.1054/mehy.1999.1044.10985909.

[158] Barde, Y.-A. Biological Roles of Neurotrophins. In Neurotrophic Factors; Hefti, F., Ed.; Springer-Verlag Berlin Heidelberg, 1999; pp 1-31. https://doi.org/10.1007/978-3-64259920-0_1.

[159] Ceni, C.; Unsain, N.; Zeinieh, M. P.; Barker, P. A. Neurotrophins in the Regulation of Cellular Survival and Death. Handb. Exp. Pharmacol. 2014, 220, 193-221. https://doi.org/10.1007/978-3-642-45106-5_8.

[160] Chao, M. V. Neurotrophins and Their Receptors: A Convergence Point for Many Signalling Pathways. Nat. Rev. Neurosci. 2003, 4 (4), 299-309. https://doi.org/10.1038/nrn1078.12671646.

[161] Hempstead, B. L. Deciphering Proneurotrophin Actions. Handb. Exp. Pharmacol. 2014, 220, 17-32. https://doi.org/10.1007/978-3-642-45106-5_2.

[162] Lu, B.; Nagappan, G.; Lu, Y. BDNF and Synaptic Plasticity, Cognitive Function, and Dysfunction. Handb. Exp. Pharmacol. 2015, 220, 223-250. https://doi.org/10.1007/978-3642-45106-5_9.

[163] Bruscolini, A.; Sacchetti, M.; La Cava, M.; Nebbioso, M.; Iannitelli, A.; Quartini, A.; Lambiase, A.; Ralli, M.; de Virgilio, A.; Greco, A. Quality of Life and Neuropsychiatric Disorders in Patients with Graves' Orbitopathy: Current Concepts. Autoimmun. Rev. 2018, 17 (7), 639-643. https://doi.org/10.1016/j.autrev.2017.12.012.29729448.

[164] Quartini, A.; Pacitti, F.; Bersani, G.; Iannitelli, A. From Adolescent Neurogenesis to Schizophrenia: Opportunities, Challenges and Promising Interventions. Biomed. Rev. 2017, 28, 66-73. https://doi.org/10.14748/bmr.v28.4452.

[165] Tore, F.; Tonchev, A.; Fiore, M.; Tuncel, N.; Atanassova, P.; Aloe, L.; Chaldakov, G. From 
Adipose Tissue Protein Secretion to Adipopharmacology of Disease. Immunol. Endocr. Metab. Agents Med. Chem. 2007, 7 (2), 149-155. https://doi.org/10.2174/187152207780363712.

[166] Chaldakov, G. N.; Aloe, L.; Tonchev, A. B.; Fiore, M. From Homo Obesus to Homo Diabesus: Neuroadipology Insight. In Molecular Mechanisms Underpinning the Development of Obesity; 2014; pp 167-178. https://doi.org/10.1007/978-3-319-12766-8_11.

[167] Chaldakov, G. N.; Fiore, M.; Tonchev, A. B.; Aloe, L. Neuroadipology: A Novel Component of Neuroendocrinology. Cell Biol. Int. 2010, 34 (10), 1051-1053. https://doi.org/10.1042/CBI20100509.20825365.

[168] Chaldakov, G. N.; Fiore, M.; Ghenev, P. I.; Stankulov, I. S.; Aloe, L. Atherosclerotic Lesions: Possible Interactive Involvement of Intima, Adventitia and Associated Adipose Tissue. Int. Med. J. 2000, 7 (1), 43-49.

[169] Chaldakov, G. N.; Fiore, M.; Tonchev, A.; Dimitrov, D.; Pancheva, R.; Rancic, G.; Aloe, L. Homo Obesus: A Metabotrophin-Deficient Species. Pharmacology and Nutrition Insight. Curr. Pharm. Des. 2007, 13 (21), 2176-2179. https://doi.org/10.2174/138161207781039616.17627549.

[170] Budni, J.; Bellettini-Santos, T.; Mina, F.; Garcez, M. L.; Zugno, A. I. The Involvement of BDNF, NGF and GDNF in Aging and Alzheimer's Disease. Aging Dis. 2015, 6 (5), 331341. https://doi.org/10.14336/AD.2015.0825.26425388.

[171] Miranda, M.; Morici, J. F.; Zanoni, M. B.; Bekinschtein, P. Brain-Derived Neurotrophic Factor: A Key Molecule for Memory in the Healthy and the Pathological Brain. Frontiers in Cellular Neuroscience. 2019. https://doi.org/10.3389/fncel.2019.00363.

[172] Vega, S. R.; Kleinert, J.; Sulprizio, M.; Hollmann, W.; Bloch, W.; Strüder, H. K. Responses of Serum Neurotrophic Factors to Exercise in Pregnant and Postpartum Women. Psychoneuroendocrinology 2011, 36 (2), 220-227. https://doi.org/10.1016/j.psyneuen.2010.07.012.20692101. 
[173] Boschen, K. E.; Klintsova, A. Y. Neurotrophins in the Brain: Interaction With Alcohol Exposure During Development. Vitam. Horm. 2017, 104, 197-242. https://doi.org/10.1016/bs.vh.2016.10.008.

[174] Feng, M.-J.; Yan, S.-E.; Yan, Q.-S. Effects of Prenatal Alcohol Exposure on Brain-Derived Neurotrophic Factor and Its Receptor Tyrosine Kinase B in Offspring. Brain Res. 2005, 1042 (2), 125-132. https://doi.org/10.1016/j.brainres.2005.02.017.15854584.

[175] Han, J. Y.; Kwon, H. J.; Ha, M.; Paik, K. C.; Lim, M. H.; Gyu Lee, S.; Yoo, S. J.; Kim, E. J. The Effects of Prenatal Exposure to Alcohol and Environmental Tobacco Smoke on Risk for ADHD: A Large Population-Based Study. Psychiatry Res. 2015, 225 (1-2), 164-168. https://doi.org/10.1016/j.psychres.2014.11.009.25481018.

[176] Abel, E. L. Paternal Alcohol Exposure and Hyperactivity in Rat Offspring: Effects of Amphetamine. Neurotoxicol. Teratol. 1993, 15 (6), 445-449. https://doi.org/10.1016/08920362(93)90063-T.8302247.

[177] Conner, K. E.; Bottom, R. T.; Huffman, K. J. The Impact of Paternal Alcohol Consumption on Offspring Brain and Behavioral Development. Alcohol. Clin. Exp. Res. 2020, 44 (1), 125140. https://doi.org/10.1111/acer.14245.31746471.

[178] Jamerson, P. A.; Wulser, M. J.; Kimler, B. F. Neurobehavioral Effects in Rat Pups Whose Sires Were Exposed to Alcohol. Dev. Brain Res. 2004, 149 (2), 103-111. https://doi.org/10.1016/j.devbrainres.2003.12.010.15063090.

[179] Kim, P.; Choi, C. S.; Park, J. H.; Joo, S. H.; Kim, S. Y.; Ko, H. M.; Kim, K. C.; Jeon, S. J.; Park, S. H.; Han, S. H.; et al. Chronic Exposure to Ethanol of Male Mice before Mating Produces Attention Deficit Hyperactivity Disorder-like Phenotype along with Epigenetic Dysregulation of Dopamine Transporter Expression in Mouse Offspring. J Neurosci Res 2014, 92, 658-670. https://doi.org/10.1002/jnr.23275.

[180] Meek, L. R.; Myren, K.; Sturm, J.; Burau, D. Acute Paternal Alcohol Use Affects Offspring Development and Adult Behavior. Physiol. Behav. 2007, 91 (1), 154-160. 
https://doi.org/10.1016/j.physbeh.2007.02.004.17433387.

[181] Hutchinson, D.; Youssef, G. J.; McCormack, C.; Wilson, J.; Allsop, S.; Najman, J.; Elliott, E.; Burns, L.; Jacobs, S.; Honan, I.; et al. Correction to: Prenatal Alcohol Exposure and Infant Gross Motor Development: A Prospective Cohort Study (BMC Pediatrics (2019) 19 (149) DOI: 10.1186/S12887-019-1516-5). BMC Pediatr. 2019, 19 (1). https://doi.org/10.1186/s12887-019-1585-5.31272396.

[182] McCormack, C.; Hutchinson, D.; Burns, L.; Youssef, G.; Wilson, J.; Elliott, E.; Allsop, S.; Najman, J.; Jacobs, S.; Rossen, L.; et al. Maternal and Partner Prenatal Alcohol Use and Infant Cognitive Development. Drug Alcohol Depend. 2018, 185, 330-338. https://doi.org/10.1016/j.drugalcdep.2017.12.038.29499553.

[183] Abel, E. L. Paternal Alcohol Consumption Affects Grooming Response in Rat Offspring. Alcohol 1991, 8 (1), 21-23. https://doi.org/10.1016/0741-8329(91)91168-2.

[184] Abel, E. L.; Tan, S. E. Effects of Paternal Alcohol Consumption on Pregnancy Outcome in Rats. Neurotoxicol. Teratol. 1988, 10 (3), 187-192. https://doi.org/10.1016/0892$0362(88) 90016-5.3211095$.

[185] Zuccolo, L.; DeRoo, L. A.; Wills, A. K.; Davey Smith, G.; Suren, P.; Roth, C.; Stoltenberg, C.; Magnus, P.; Smith, G. D.; Suren, P.; et al. Erratum: Pre-Conception and Prenatal Alcohol Exposure from Mothers and Fathers Drinking and Head Circumference: Results from the Norwegian Mother-Child Study (MoBa). Sci. Rep. 2017, 7, 45877. https://doi.org/10.1038/srep45877.

[186] Abel, E. L. Paternal Behavioral Mutagenesis. Neurotoxicology 1989, 10 (3), 335345.2626212.

[187] Liang, F.; Diao, L.; Jiang, N.; Zhang, J.; Wang, H.-J.; Zhou, W.-H.; Huang, G.-Y.; Ma, D. Chronic Exposure to Ethanol in Male Mice May Be Associated with Hearing Loss in Offspring. Asian J. Androl. 2015, 17 (6), 985-990. https://doi.org/10.4103/1008$682 X .160267$. 
[188] Liang, F.; Diao, L.; Liu, J.; Jiang, N.; Zhang, J.; Wang, H.; Zhou, W.; Huang, G.; Ma, D. Paternal Ethanol Exposure and Behavioral Abnormities in Offspring: Associated Alterations in Imprinted Gene Methylation. Neuropharmacology 2014, 81, 126-133. https://doi.org/10.1016/j.neuropharm.2014.01.025.

[189] Przybycien-Szymanska, M. M.; Rao, Y. S.; Prins, S. A.; Pak, T. R. Parental Binge Alcohol Abuse Alters F1 Generation Hypothalamic Gene Expression in the Absence of Direct Fetal Alcohol Exposure. PLoS One 2014, 9 (2), 89320. https://doi.org/10.1371/journal.pone.0089320.24586686.

[190] Xia, R.; Jin, L.; Li, D.; Liang, H.; Yang, F.; Chen, J.; Yuan, W.; Miao, M. Association Between Paternal Alcohol Consumption Before Conception and Anogenital Distance of Offspring. Alcohol. Clin. Exp. Res. 2018, 42 (4), 735-742. https://doi.org/10.1111/acer.13595.29315635.

[191] Hazlett, L. D.; Barrett, R. P.; Berk, R. S.; Abel, E. L. Maternal and Paternal Alcohol Consumption Increase Offspring Susceptibility to Pseudomonas Aeruginosa Ocular Infection. Ophthalmic Res. 1989, 21 (5), 381-387. https://doi.org/10.1159/000266905.2513544.

[192] Nelson, B. K.; Brightwell, W. S.; MacKenzie-Taylor, D. R.; Burg, J. R.; Massari, V. J. Neurochemical, but Not Behavioral, Deviations in the Offspring of Rats Following Prenatal or Paternal Inhalation Exposure to Ethanol. Neurotoxicol. Teratol. 1988, 10 (1), 15-22. https://doi.org/10.1016/0892-0362(88)90062-1.2895419.

[193] Little, R. E.; Sing, C. F. Father's Drinking and Infant Birth Weight: Report of an Association. Teratology 1987, 36 (1), 59-65. https://doi.org/10.1002/tera.1420360109.3672378.

[194] Abel, E. L. Paternal Alcohol Consumption: Effects of Age of Testing and Duration of Paternal Drinking in Mice. Teratology 1989, 40 (5), 467-474. https://doi.org/10.1002/tera.1420400509. 
[195] Chang, R. C.; Wang, H.; Bedi, Y.; Golding, M. C. Preconception Paternal Alcohol Exposure Exerts Sex-Specific Effects on Offspring Growth and Long-Term Metabolic Programming. Epigenetics and Chromatin 2019, 12 (1), 1-17. https://doi.org/10.1186/s13072-019-02540.30670059 .

[196] Chang, R. C.; Thomas, K. N.; Bedi, Y. S.; Golding, M. C. Programmed Increases in LXR $\alpha$ Induced by Paternal Alcohol Use Enhance Offspring Metabolic Adaptation to High-Fat Diet Induced Obesity. Mol. Metab. 2019, 30 (October), 161-172. https://doi.org/10.1016/j.molmet.2019.09.016.31767168.

[197] Abel, E. L. Rat Offspring Sired by Males Treated with Alcohol. Alcohol 1993, 10 (3), 237242. https://doi.org/10.1016/0741-8329(93)90042-M.8507394.

[198] Sittig, L. J.; Redei, E. E. Paternal Genetic Contribution Influences Fetal Vulnerability to Maternal Alcohol Consumption in a Rat Model of Fetal Alcohol Spectrum Disorder. PLoS One 2010, 5 (4), e10058. https://doi.org/10.1371/journal.pone.0010058.20383339.

[199] Tanaka, H.; Suzuki, N.; Arima, M. Experimental Studies on the Influence of Male Alcoholism on Fetal Development. Brain Dev. 1982, 4 (1), 1-6.7039389.

[200] Rompala, G. R.; Mounier, A.; Wolfe, C. M.; Lin, Q.; Lefterov, I.; Homanics, G. E. Heavy Chronic Intermittent Ethanol Exposure Alters Small Noncoding RNAs in Mouse Sperm and Epididymosomes. Front. Genet. 2018, 9 (FEB), 1-14.

https://doi.org/10.3389/fgene.2018.00032.

[201] Ouko, L. A.; Shantikumar, K.; Knezovich, J.; Haycock, P.; Schnugh, D. J.; Ramsay, M. Effect of Alcohol Consumption on CpG Methylation in the Differentially Methylated Regions of H19 and IG-DMR in Male Gametes - Implications for Fetal Alcohol Spectrum Disorders. Alcohol. Clin. Exp. Res. 2009, 33 (9), 1615-1627. https://doi.org/10.1111/j.15300277.2009.00993.x.19519716.

[202] Haycock, P. C.; Ramsay, M. Exposure of Mouse Embryos to Ethanol during Preimplantation Development: Effect on DNA Methylation in the H19 Imprinting Control Region. Biol 
Reprod 2009, 81, 618-627.

[203] Gundogan, F.; Elwood, G.; Longato, L.; Tong, M.; Feijoo, A.; Carlson, R. I.; Wands, J. R.; de la Monte, S. M. Impaired Placentation in Fetal Alcohol Syndrome. Placenta 2008, 29 (2), 148-157. https://doi.org/10.1016/j.placenta.2007.10.002.18054075.

[204] Shukla, P. K.; Sittig, L. J.; Ullmann, T. M.; Redei, E. E. Candidate Placental Biomarkers for Intrauterine Alcohol Exposure. Alcohol. Clin. Exp. Res. 2011, 35 (3), 559-565. https://doi.org/10.1111/j.1530-0277.2010.01373.x.21143252.

[205] Rathod, R. S.; Ferguson, C.; Seth, A.; Baratta, A. M.; Plasil, S. L.; Homanics, G. E. Effects of Paternal Preconception Vapor Alcohol Exposure Paradigms on Behavioral Responses in Offspring. Brain Sci. 2020, 10 (9), 1-23.

https://doi.org/10.3390/brainsci10090658.32971974.

[206] Kagan-Krieger, S.; Selby, P.; Vohra, S.; Koren, G. Paternal Alcohol Exposure and Turner Syndrome. Alcohol Alcohol 2002, 37 (6), 613-617.

https://doi.org/10.1093/alcalc/37.6.613.12414557.

[207] Radford, E. J. Exploring the Extent and Scope of Epigenetic Inheritance. Nat. Rev. Endocrinol. 2018, 14 (6), 345-355. https://doi.org/10.1038/s41574-018-0005-5.29666451.

[208] Mead, E. A.; Sarkar, D. K. Fetal Alcohol Spectrum Disorders and Their Transmission through Genetic and Epigenetic Mechanisms. Front. Genet. 2014, 5, 154. https://doi.org/10.3389/fgene.2014.00154. 


\begin{tabular}{|l|l|l|l|}
\hline $\begin{array}{l}\text { Congenital } \\
\text { malformations }\end{array}$ & Organs and apparats & Behavioral & $\begin{array}{l}\text { Cognitive } \\
\text { functioning }\end{array}$ \\
\hline $\begin{array}{l}\text { Abnormal facial } \\
\text { features: flat nasal } \\
\text { bridge, smooth ridge } \\
\text { between the nose and } \\
\text { upper lip, thin upper } \\
\text { lip, extra crease in the } \\
\text { outer ears, } \\
\text { An upturned nose }\end{array}$ & Hearing problems & Sleep problems & Learning disabilities \\
\hline $\begin{array}{l}\text { Curved pinky finger } \\
\text { height }\end{array}$ & Heart & Sucking problems & $\begin{array}{l}\text { Problems following } \\
\text { directions }\end{array}$ \\
\hline $\begin{array}{l}\text { Smaller head size } \\
\text { Kidneys }\end{array}$ & Endocrine disruptions & Hyperactive behavior & $\begin{array}{l}\text { Difficulty } \\
\text { understanding the } \\
\text { consequences of their } \\
\text { actions }\end{array}$ \\
\hline Low body weight & Bones & Poor social skills & Poor reasoning skills \\
\hline Immune dysfunction & & & $\begin{array}{l}\text { Speech and language } \\
\text { delays }\end{array}$ \\
\hline
\end{tabular}

Table 1. Fetal alcohol spectrum disorders common clinical features. 


\section{Figure 1 caption}

Epigenetics refers to biochemical changes in chromatin structure that can modify gene expression without altering the DNA sequence. Paternal preconceptual alcohol consumption (PPAC) causes epigenetic alterations in male sperm which have been related to paternal FASD:

1) PPAC alters gene expression with 3 major processes, A) enhancement of the catabolism and loss of methyl groups, which in turn disrupts subsequent SAM-dependent transmethylation reactions of the folate pathway, which are lastly required for DNA methylation; B) nucleosomal remodeling via histone modifications; C) abnormal microRNA expression

2) PPAC also enhances oxidative stress response due to the metabolism of ethanol to acetaldehyde, catalyzed either by alcohol dehydrogenase, CYP2E1, or catalase, leading to the generation of ROS and modifying the intracellular redox state, ultimately causing neuronal cell death and altered gene expression as a result of DNA oxidation;

3) global upregulation of neuroendocrine stress response regulated by the HPA axis and the linked drinking behavior have been related to epigenetic modulation of neurotrophins and POMC genes and variations of the pathways regulating mood, emotion, serotonergic tone.

$\mathrm{ADH}$, alcohol dehydrogenase; ALDH, acetaldehyde dehydrogenase; BNDF, brain-derived neurotrophic factor; CYP2E1, cytochrome P450 2E1; EtOH, ethanol; FASD, fetal alcohol spectrum disorders; HPA, hypothalamic-pituitary-adrenal; HTR2C, 5-Hydroxytryptamine Receptor 2C; NGF, nerve growth factor; p75NTR, low-affinity pan-neurotrophins receptor; POMC, proopiomelanocortin; ROS, reactive oxygen species; SAM, S-adenosyl-L-methionine; SLC6A4, Solute Carrier Family 6 Member 4. 


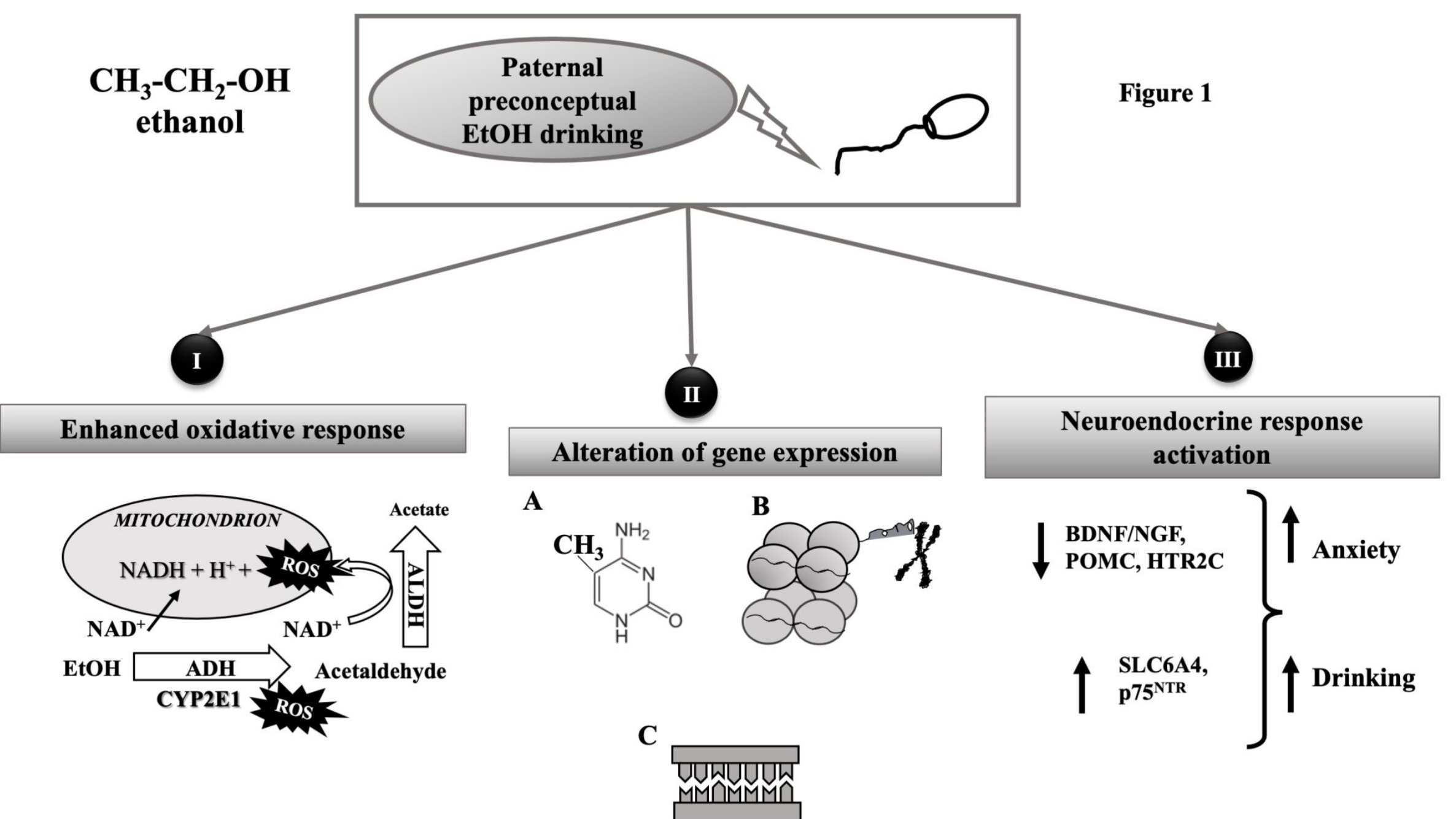




\title{
Transgenerational Abnormalities Induced by Paternal Preconceptual
}

\author{
Alcohol Drinking. Findings from Humans and Animal Models
}

\author{
Sergio Terracina ${ }^{1}$, Giampiero Ferraguti ${ }^{1}$, Luigi Tarani ${ }^{2}$, Marisa Patrizia Messina ${ }^{3}$, Marco \\ Lucarelli $^{1}$, Mario Vitali ${ }^{4}$, Simone De Persis ${ }^{5}$, Antonio Greco ${ }^{6}$, Antonio Minni ${ }^{6}$, Antonella \\ Polimeni $^{7}$, Mauro Ceccanti ${ }^{8}$, Carla Petrella ${ }^{9}$ and Marco Fiore*9
}

1 - Department of Experimental Medicine, Medical Faculty, Sapienza University of Rome, Italy

2 - Department of Pediatrics, Medical Faculty, "Sapienza" University of Rome, Italy

3 - Department of Gynecology, Obstetrics and Urology, Sapienza University of Rome, Italy

4 - ASUR Marche, AV4, Ancona, Italy

5 - ASL Rieti, Italy

6 - Department of Sense Organs, Sapienza University Hospital of Rome, Italy

7 - Department of Odontostomatological and Maxillofacial Sciences, Sapienza University of Rome, Italy

8 - SITAC, Società Italiana per il Trattamento dell'Alcolismo e le sue Complicanze, Rome, Italy

9 - Institute of Biochemistry and Cell Biology (IBBC-CNR), Rome, Italy

*Corresponding author:

Marco Fiore, Ph.D.

Institute of Biochemistry and Cell Biology (IBBC-CNR), Rome, Italy

Department of Sense Organs, Sapienza University of Rome, Rome, Italy

Viale del Policlinico, 155 - 00161 Rome, Italy

e-mail: marco.fiore@enr.it

\section{Acknowledgments}

The authors thank Sapienza University of Rome and IBBC-CNR for supporting their study.

\section{Conflict of interest}

The authors declare that they have no conflict of interest.

\section{Funding}

This research did not receive any specific grant from funding agencies in the public, commercial, or not-for-profit sectors. 